University at Albany, State University of New York

Scholars Archive

Educational Theory and Practice Faculty

Scholarship

Educational Theory and Practice

Spring 4-15-2018

\title{
Co-Organizing the Collective Journey of Inquiry with Idea Thread Mapper
}

Jianwei Zhang

University at Albany, State University of New York, jzhang1@albany.edu

Dan Tao

University at Albany, State University of New York

Mei-hwa Chen

University at Albany, State University of New York

Yanqing Sun

University at Albany, State University of New York

Darlene Judson

University at Albany, State University of New York

See next page for additional authors

Follow this and additional works at: https://scholarsarchive.library.albany.edu/etap_fac_scholar

Part of the Curriculum and Instruction Commons, Educational Psychology Commons, and the Educational Technology Commons

\section{Recommended Citation}

Zhang, Jianwei; Tao, Dan; Chen, Mei-hwa; Sun, Yanqing; Judson, Darlene; and Naqvi, Sarah, "Co-Organizing the Collective Journey of Inquiry with Idea Thread Mapper" (2018). Educational Theory and Practice Faculty Scholarship. 24.

https://scholarsarchive.library.albany.edu/etap_fac_scholar/24

This Article is brought to you for free and open access by the Educational Theory and Practice at Scholars Archive. It has been accepted for inclusion in Educational Theory and Practice Faculty Scholarship by an authorized administrator of Scholars Archive. For more information, please contact scholarsarchive@albany.edu. 


\section{Authors}

Jianwei Zhang, Dan Tao, Mei-hwa Chen, Yanqing Sun, Darlene Judson, and Sarah Naqvi 
See discussions, stats, and author profiles for this publication at: https://www.researchgate.net/publication/323153564

\section{Co-Organizing the Collective Journey of Inquiry with Idea Thread Mapper}

Article in Journal of the Learning Sciences · January 2018

CITATIONS

3

6 authors, including:

(2) Jianwei Zhang

University at Albany, The State University of New York

70 PUBLICATIONS 1,280 CITATIONS

SEE PROFILE

(a) Mei-Hwa Chen

University at Albany, The State University of New York

47 PUBLICATIONS 1,205 CITATIONS

SEE PROFILE

Some of the authors of this publication are also working on these related projects:

National Science Foundation View project

Fostering Collective Progress in Online Discourse for Sustained Knowledge Building. View project
READS

471

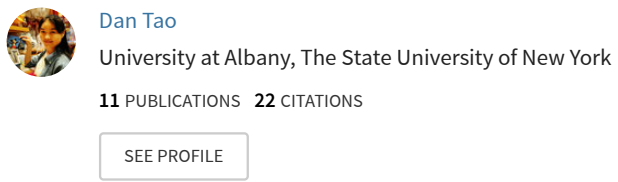


Zhang, J., Tao, T., Chen, M-H., Sun, Y., Judson D., \& Naqvi, S. (2018). Co-Organizing the Collective Journey of Inquiry With Idea Thread Mapper. Journal of the Learning Sciences.

To link to this article: https://doi.org/10.1080/10508406.2018.1444992

\section{Co-Organizing the Collective Journey of Inquiry with Idea Thread Mapper}

Jianwei Zhang ${ }^{1}$, Dan Tao ${ }^{1}$, Mei-Hwa Chen ${ }^{2}$, Yanqing Sun ${ }^{1}$, Darlene Judson ${ }^{1}$, Sarah Naqvi ${ }^{3}$

1 Department of Educational Theory and Practice

University at Albany, SUNY

2 Department of Computer Science

University at Albany, SUNY

3 Dr. Eric Jackman Institute of Child Study

University of Toronto

Correspondence:

Jianwei Zhang

Department of Educational Theory and Practice

University at Albany

State University of New York

Phone: 518-442-4007

Email: jzhang1@albany.edu 


\begin{abstract}
This research integrates theory building, technology design, and design-based research to address a central challenge pertaining to collective inquiry and knowledge building: how can studentdriven, ever-deepening inquiry processes become socially organized and pedagogically supported in a community? Different from supporting inquiry using pre-designed structures, we propose reflective structuration as a social and temporal mechanism by which members of a community co-construct/re-construct shared inquiry structures to shape and guide their ongoing knowledge building processes. Idea Thread Mapper (ITM) was designed to help students and their teacher monitor emergent directions and co-organize the unfolding inquiry processes over time. A study was conducted in two upper primary school classrooms that investigated electricity with the support of ITM. Qualitative analyses of classroom videos and observational data documented the formation and elaboration of shared inquiry structures. Content analysis of the online discourse and student reflective summaries showed that in the classroom with reflective structuration, students made more active and connected contributions to their online discourse, leading to deeper and more coherent scientific understandings.
\end{abstract}




\section{Co-Organizing the Collective Journey of Inquiry with Idea Thread Mapper}

Education needs to prepare students for sustained, collaborative, and creative work with knowledge that is essential to the 21 st century economy and society. Recent reforms in science education particularly highlight the need to engage students in authentic and sustained scientific practices by which knowledge is developed (National Research Council, 2012; NGSS Lead States, 2013). Contributing to addressing these needs, researchers have developed various learning models that engage students in collective inquiry and knowledge building. Students in a classroom community participate in joint inquiry practices to advance their shared understanding with the support of social technologies (Bielaczyc \& Collins, 2006; Brown \& Campione, 1996; Scardamalia \& Bereiter, 2014; Slotta, Suthers, \& Roschelle, 2014). Major progress has been achieved in understanding the specific socio-cognitive processes of student inquiry and interaction for collaborative knowledge building (Bell \& Linn, 2000; Hakkarainen, 2003; Hmelo-Silver, 2004; Järvelä \& Hadwin, 2013; Roschelle, 1992; van Aalst, 2009; Zhang et al., 2007).

However, despite the advances, the field still does not offer clear guidance about how to sustain students' inquiry and collaboration over many weeks or months to leverage classroom transformation (Stahl \& Hesse, 2009). An important challenge is that classroom practices should not only sustain long-term inquiry and collaboration but should also develop student agency. Underlying this challenge is a knowledge gap regarding how student-driven inquiry and dynamic collaboration may be socially organized and pedagogically supported in classrooms. The reported work attempts to address this gap through integrated efforts, which include (a) theory 
building focused on co-constructing collective inquiry structures to support student agency over sustained knowledge building practices; (b) the design of Idea Thread Mapper (ITM) to help students monitor emerging directions and co-organize their unfolding inquiry over time; and (c) a design-based research study to elaborate the processes by which students co-construct inquiry structures using ITM and to examine the impact of such efforts on student knowledge building. This paper first presents a brief literature review on collective inquiry and knowledge building, which is followed by the three main sections: theory building, technology design, and a designbased research study.

\section{Collective Inquiry and the Challenge of Implementation}

In collective inquiry, students work as a community that engages in joint inquiry-based practices to build and advance collective knowledge, which benefits and leverages student personal growth (Bielaczyc \& Collins, 2006; Brown \& Campione, 1996; Scardamalia \& Bereiter, 2014; Slotta et al., 2014). A model of collective inquiry is the Knowledge Building pedagogy, which aims to transform classrooms into knowledge building communities in line with how realworld knowledge-creating organizations operate (Scardamalia \& Bereiter, 2014). Working as a community, students in a classroom engage in sustained idea improvement to advance the "state of the art" of their community's knowledge- their collective knowledge as a social product. They identify and work on problems of understanding, contribute their ideas to a public space, engage in progressive discourse and experimentation, and use a variety of resources to deepen and improve their ideas. These knowledge processes are supported using collaborative technology platforms such as Knowledge Forum (Scardamalia \& Bereiter, 2014). Classroom practices to support knowledge building require students to take on high-level agency and collective responsibility for setting and deepening knowledge goals, charting the courses of 
inquiry, reviewing collective and personal progress, and coordinating their collaborative efforts (Scardamalia, 2002; Zhang et al., 2009). A large body of research has examined the processes and outcomes of knowledge building (see Chen \& Hong, 2016 for a review). The findings reveal students' productive moves of knowledge building, including generating progressive questions, theorizing and explaining, examining ideas using evidence, constructive reading, interactive idea build-on, and ongoing reflection on collective advances and personal contributions (van Aalst \& Chan, 2007; Chuy, Zhang, Resendes, Scardamalia, \& Bereiter, 2011; Hakkarainen, 2003; van Aalst, 2009; Zhang et al., 2007). Many of these patterns are consistent with the productive interactions captured in other collaborative inquiry settings (Damşa, 2014; Hmelo-Silver, 2003; Mercer \& Littleton, 2007).

Efforts to support and sustain student inquiry and collaboration in classrooms have adopted different approaches ranging from scripted to more open-ended, principle-based designs (see Bereiter, Cress, Fischer, Hakkarainen, Scardamalia, \& Vogel, 2017 for a debate). A scripted approach scaffolds learners using carefully designed scripts, which specify, sequence, and distribute various task operations and activity procedures among learners in order to guide effective interactions (Kirschner \& Erkens, 2013). The scripts may be adapted and integrated through the real-time orchestration of the teacher, who manages the activities involving different tools and media (Dillenbourg, Järvelä, \& Fischer, 2009).

At the other end of the spectrum, researchers have explored more open-ended learning designs (Hannafin, Land, \& Oliver, 1999). As a specific model, Knowledge Building pedagogy adopts a principle-based approach (Scardamalia, 2002; Zhang et al., 2011). Instead of relying on pre-defined inquiry tasks and procedures, the teacher works with his/her students to chart the deepening process of inquiry as informed by a set of knowledge building principles. These 
include authentic problems and real ideas, collective cognitive responsibility, epistemic agency, idea improvement, knowledge building discourse, embedded and transformative assessment, and so forth (Scardamalia, 2002). In a knowledge building initiative that extends over several weeks or months, students work with their teacher to define what they need to understand, plan and carry out inquiry activities, and reflect on progress while identifying deeper problems for continual idea improvement. The inquiry process continually evolves and deepens through the "collaborative improvisation" (Sawyer, 2004) of the community members without relying on pre-scripted procedures (Zhang et al., 2011). With such classroom dynamics comes a high-level symmetry in teacher-student interactions (Tabak \& Baumgartner, 2004), with all members of the community contributing to the flow of the classroom work.

A challenge faced by both approaches is how to provide structures for students while also engaging their high-level agency. The scripted approach focuses on guiding students with predesigned structures such as inquiry tasks and collaboration procedures, which show positive effects on student performance (Fischer, Kollar, Stegmann, \& Wecker, 2013) especially when students lack inquiry-based experience. However, having students work on pre-defined tasks and procedures may undermine their agency and future-oriented imagination, which are essential to dynamic creative practices (Miettinen \& Virkkunen, 2005). Long-term, creative inquiry processes involve highly dynamic interactions (Sawyer, 2007) that are difficult to predict and pre-script. Learning designs to support creative inquiry over weeks or months need to flexibly fit into such dynamics, rather than control them (Zhang et al., 2011; see also O'Neill, 2016).

The principle-based approach to knowledge building embraces flexible classroom dynamics that are needed for creative knowledge processes in which students develop high-level agency (Zhang et al., 2011). To guide classroom implementation, this approach needs to clarify 
how the dynamic knowledge processes can be effectively supported with various structures. Although researcher have documented productive knowledge building as achieved by various classroom communities (see Chen \& Hong, 2016 for review), which are often facilitated by veteran teachers, their success is largely a mystery to other teachers, who would like to adopt knowledge building but do not know how to get started. It is unclear how student-driven, openended, interactive inquiry processes can become socially organized and pedagogically supported while addressing practical curriculum and contextual constraints. This paper presents three sections - theory, technology, and research — to address this important challenge associated with the principle-based approach.

\section{Theory Building: Co-Organizing Knowledge Practices through Reflective Structuration}

Our theory-building efforts to solve the above challenge start with a focus on the social practices of working with knowledge: knowledge practices (Hakkarainen, 2009). Knowledge practices represent a social system that rises above the specific knowledge building moves and processes reviewed previously (Chuy et al., 2011; Hakkarainen, 2003; van Aalst, 2009; Zhang et al., 2007). Knowledge practices developed in each classroom work as a social system to channel and sustain students' specific socio-cognitive moves of knowledge building in a specific context. As Hakkarainen (2009) argues, "to truly contribute to educational transformation, pedagogical approaches have to be embedded in locally cultivated 'knowledge practices' that channel the participants' intellectual efforts in a way that elicits collective advancement of knowledge." (p.

213) Research shows that creative knowledge practices in contemporary organizations take place as dynamic social systems, which are flexibly structured to encourage members' participatory control, opportunistic collaboration, and cross-fertilization of ideas that often lead to unexpected 
advances (Gloor, 2006; Engeström, 2008; Sawyer, 2007; Williams \& Yang, 1999; Zhang et al., 2009).

To explore how classrooms may support dynamic knowledge practices in a way that engages student agency, our previous studies analyzed a set of design-based research studies conducted in primary school classrooms (Tao \& Zhang, in press; Tao, Zhang, \& Huang, 2015; Zhang et al., 2009; Zhang \& Messina, 2010). For example, one study analyzed the design improvements in a Grade 4 classroom over three successive school years (Zhang et al., 2009). Each year involved a cohort of students who worked together to build knowledge about light. Productive knowledge outcomes were achieved through opportunistic collaboration and interaction in which students grouped and regrouped around emergent goals to advance collective knowledge. Detailed analysis of the classroom processes revealed a unique type of support structures that were not pre-designed but co-constructed by the classroom members over time (Zhang, 2013; Zhang \& Messina, 2010). Instead of assigning inquiry tasks and procedures, the teacher focused his role on engaging students to generate progressive questions and ideas; tracing emerging inquiry interests, progress, and needs; and facilitating reflective conversations among students to formulate shared inquiry directions and guidelines. Specifically, students generated interest-driven questions and then co-reviewed their questions to create a shared "mission statement," which was to understand how light works. As the inquiry work proceeded, they further reviewed their collaborative discourse to identify major directions of inquiry (e.g., shadows, colors) and created new online spaces based on these directions. The shared mission statement, research directions, and theme-based online spaces were used by students to guide their participation, discourse, and reflection on progress. With such co-constructed structures, students did not rely on their teacher to tell them what to do. 
Drawing upon the analyses of co-constructed inquiry structures, we developed a reflective structuration framework to explain how student-driven, dynamic knowledge practices may be socially organized and supported in classrooms (Tao \& Zhang, in press; Tao, Zhang, \& Gao, 2017; Zhang, 2013). In a nutshell, reflective structuration refers to the reflective processes by which members of a community co-construct collective inquiry structures over time to channel their personal and collaborative actions, as a dynamic system of knowledge practices. Student-driven, dynamic knowledge practices can be socially organized and sustained through co-constructing collective inquiry structures as the work proceeds in response to emergent inquiry directions and needs. The structures can be used to inform and guide students' actions and interactions to advance knowledge, which, over time, may give rise to further adaptation and reconstruction of inquiry structures.

At the heart of this framework is a change of design thinking from pre-scripting to emergent co-construction of inquiry structures. As analogies, one may think of scripted structures as designed paths in a park created based on the designer's blueprint to direct people's movement; while co-constructed structures are similar to desire lines-also known as "desire paths" or "social trails" - which are formed naturally by pedestrians as they take the best paths to get to their points of interest. The designer can allow people to walk around in a relatively open landscape, wait for the desire lines to emerge, and then pave the paths and set up direction signs to guide people's movement. This "desire line" approach to discover emergent patterns of interactions and create adaptive structures accordingly represents a productive strategy to design complex social systems and spaces (Johnson, 2001; Sawyer, 2005). The reflective structuration framework applies the "desire line" strategy to organizing dynamic knowledge practices in classrooms. As the Grade 4 light study suggests, the teacher can work with students to engage in 
open exploration to generate diverse ideas and questions in interactive discourse, and then to review the connections and formulate shared inquiry directions and theme-based spaces, which serve to shape members' further contribution and interaction. The teacher and students share the responsibility to monitor emergent changes and shape the unfolding courses of inquiry for continual knowledge advancement.

We conceptualize collective inquiry structures in light of the social practice theories in sociology and organizational science (Archer, 1995; Giddens, 1984; Sewell, 1992). According to these theories, a social practice sustains over time in a continual and coherent manner largely through the formation and use of social structures (Archer, 1982; Giddens, 1984; Sewell, 1992). Giddens (1984) uses the term "structuration" to emphasize that structures, as systems of social action, are not static but in the process of being continuously produced and reproduced. Building on Giddens, Sewell (1992) defines social structures as "sets of mutually sustaining schemas and resources that empower and constrain social action and that tend to be reproduced by that social action." (p. 19) The schemas of practices, which are reified using various resources and artifacts, serve as interpretative frames and mediating mechanisms to guide participants' ongoing actions and interactions; and in the same process, the schemas of practices are continually reproduced and transformed, leading to dynamic changes in said practice.

In light of the above theories, we define collective inquiry structures as emergent social structures underlying a community's knowledge practices, which provide shared interpretative frames of the knowledge practices including the nature and goal of the community's inquiry work and how the work should be organized and carried out. Such structures serve as a social mediating mechanism to help channel students' ongoing participation, action, and collaboration. In the literature, there is already the concept of "participation structures" that focuses on social 
roles and interaction moves (Stahl, Koschmann, \& Suthers, 2014). The concept of "collective inquiry structures" captures the systematic features of the knowledge practices of a community: the shared knowledge goals, inquiry processes, and social participation organization, as informed by the guiding principles and values of the community. In a dynamic knowledge building community, such structures emerge and adapt over time through members' constructive interactions. We unpack this process by elaborating the following three specific conceptual points.

\section{(a) Members in a community can co-construct inquiry structures as they build domain}

\section{knowledge.}

As members build collective knowledge through interactive inquiry and discourse focusing on content-specific questions and ideas, they co-construct collective inquiry structures to frame/reframe their shared practices to inform members' interactions and contributions. The two levels of construction intertwine to sustain the unfolding knowledge practices. Members' ongoing actions and interaction for knowledge building give rise to the emergent construction of collective inquiry structures, which further influence member's knowledge building actions and interactions. Our studies identified various inquiry structures co-constructed by students with their teachers to support their knowledge building actions and interactions (Tao et al., 2015; Tao \& Zhang, in press; Tao, Zhang, \& Gao, 2017; Zhang, 2013). As Table 1 shows, the structures provide shared framing of the unfolding knowledge practices along several dimensions, including what should be investigated for what goals, how the community should carry out its research, discourse, and collaboration, who interacts with whom for what purposes, and more fundamentally, why the community should operate in certain ways, as justified based on its principles and values. 
Insert Table 1 about here

Among the various structures, a knowledge building community needs to develop shared framing of what the community should investigate: the core objects of inquiry, which are largely open-ended in creative knowledge practices (Knorr Cetina, 2001). An object of inquiry is an epistemic element (thing) to be investigated for conceptual understanding or practical application, such as a scientific phenomenon (e.g., rainbow), concept (e.g., wave), or device (e.g., lens). In a community, such objects of inquiry serve as the shared focus for members' joint attention and efforts, signifying the needs of knowledge to be addressed through the unfolding strands of inquiry. Focusing on the objects of inquiry, students develop new understanding while identifying new and deeper issues to be investigated. Hence the objects of inquiry are openended and interrelated, projecting into possible future directions of inquiry (Knorr Cetina, 2001). For example, in the aforementioned Grade 4 light study, students defined light as the high-level overarching object of inquiry, the investigation of which led to the emergence of a range of related objects: shadows, rainbows, lenses, and so forth. Each object emerged from members' inquiry in specific socio-material contexts (e.g., interacting with a prism). Reflecting on initial ideas and interests related to these objects helped to identify the emerging "desire lines" in the community's knowledge space: the unfolding strands of inquiry and discourse to be pursued. Deeper knowledge gaps were identified as progress was made (e.g., why are the colors in rainbows always in the same order?) (Zhang et al., 2007). The co-constructed inquiry directions were reified using various representations and resources, such as co-creating an evolving list of overarching questions to highlight what the community needed to research. Students used the 
structures as references to monitor progress and plan for personal and joint efforts (Zhang, 2013).

\section{(b) There is a temporal interplay between the two layers of construction.}

There is a dynamic temporal interplay between the two layers of construction to build collective inquiry structures while building and advancing domain knowledge. With the temporal dimension, the inquiry process of a community can be progressively organized to provide timely guidance and support while at the same time remaining dynamic and open-ended. We elaborate the temporal interplay in light of the social practice theories (Archer, 1982, 1995; Sewell, 1992). First, a classroom community appropriates and builds on existing structures, which have emerged from past interactions of the community or from the larger school context, to formulate initial inquiry structures. For example, the adopted structure may be a content area specified in the school's curriculum or a specific format to organize student notebooks. The initial inquiry structures serve to set up a largely open space for students to carry out exploratory inquiry and discourse interactions. The structures mediate (but do not determine) members' inquiry actions and interactions through their reflective use of the structure to monitor what they are inquiring and how their community operates. The ongoing interactions driven by students' diverse input give emergence to new inquiry directions and connections as the "desire lines" in the community's knowledge space. Such changes in turn lead to further structural elaboration and modification, as intended or unintended (unpredictable) consequences. New structures are progressively constructed/adapted in the reflection of the evolving landscape of the community's knowledge work to address the emergent needs and opportunities. The new or modified structures then become part of the contexts for the subsequent inquiry actions, guiding students' deeper inquiry efforts.

In this process, there are also ongoing two-way interactions between the micro-level 
structures constructed within the local classroom and those of the larger institutions (e.g., a school or educational system). While the macro-level structures influence the micro-level structures, locally constructed micro-level structures may ultimately generalize into the larger institution, contributing to broader change (Poole \& DeSanctis, 1992).

\section{(c) Co-constructing inquiry structures serves as a means to fostering student agency and}

\section{collective responsibility.}

The temporal collective process to appropriate, build, use, and elaborate/modify inquiry structures as the knowledge building work unfolds provides a means to progressively engaging students' agency. Through co-constructing shared inquiry structures, students enact collective cognitive responsibility (Scardamalia, 2002; Zhang et al., 2009) for charting and deepening the courses of inquiry to advance their community's knowledge. Specifically, in an inquiry initiative, students may start their work with initial structures incorporated by their teacher; as their work proceeds, they can review emergent changes in their community and form new and more elaborated structures to organize their collective inquiry. The structures can be used to inform students' personal participation and collaborative interactions on a daily basis without relying on the teacher to guide them through each step of the inquiry. Thus, co-constructed inquiry structures help to both empower and contextualize student epistemic agency. Students can position and direct their ongoing efforts in connection with the evolving agenda and context of their community to make intentional advances. Their agency is reflected in their capability to work with the community's existing structures to make productive contributions; to select and reinterpret the structures in flexible ways; to monitor emerging changes as their knowledge work deepens; and to make personal and collaborative input to reshaping the inquiry structures over time. Students' personal interests, experiences, and beliefs are brought to bear in this interactive 
process to modify shared inquiry structures. Such changes may create an impact on the unfolding courses and actions of inquiry in their community. With new technology designs to make the inquiry structures visible, the inquiry structures generated in a classroom may further be shared with other classrooms that engage in knowledge building in the related areas, creating a broader and more lasting impact (Zhang, Bogouslavsky, \& Yuan, 2017).

As a related point, reflective structuration connects with the recent research on the socially shared regulation of collaborative learning. Learners plan, monitor, and adapt collaborative processes to optimize personal contributions to collective outcomes (Järvelä \& Hadwin, 2013). However, research in this area has been focused on how learners regulate their participation within designed structures. Students' regulatory role is often limited to following the directions, dividing up the given tasks, and meeting the requirements (Rogat \& LinnenbrinkGarcia, 2011).

The reflective structuration perspective highlights important needs of research and design. Particularly, research on collaborative learning and knowledge building needs to (a) systemically investigate the array of structures dynamically formed in knowledge building communities to constitute the social system of knowledge practices (see Table 1); (b) examine how the structures are appropriated, co-constructed, represented, used, and adapted, through what kinds of interactional input from students and their teacher, and with what impact; (c) understand how the various structural elements relate to one another to mediate students' knowledge building actions, with what impact on student agency and knowledge productivity; (d) test new designs of collaborative environments and analytics to discover emergent "desire lines" from student ongoing interactions and support the co-construction of inquiry structures; and (e) design systematic support for new teachers and emerging knowledge building communities to work 
with the reflective structuration process to implement dynamic knowledge practices. Addressing these interrelated issues apparently takes long-term research. In this article, we focus on (b) and (d) to present our design of a software tool to support the co-construction of inquiry structures and a design-based research study to examine how an upper primary classroom co-constructed inquiry structures to support members' knowledge building over time.

\section{Technology Design: Idea Thread Mapper}

The reflective structuration framework suggests the need to discover and capitalize on emergent "desire lines" in collaborative online interactions to support student-driven inquiry. Instead of using pre-designed structures to specify what the community should research following what processes, collaborative environments for knowledge building need to incorporate supports for students and their teacher to monitor emerging directions and coconstruct shared inquiry structures over time. Current collaborative environments lack such support. In online forums and chatting, student ideas are recorded in individual online posts in distributed discourse. It is difficult for students and their teacher to monitor the collective landscape (e.g., emerging directions and strands of inquiry) formed and altered through the distributed discourse and interactions in long-term inquiry (Hewitt, 2001; Suthers, Vatrapu, Medina, Joseph, \& Dwyer, 2008). Without a clear awareness of their community's goals, directions, and progress, students' discourse entries are often ill-grounded and disconnected, lacking progressive deepening moves (Zhang, 2009).

To support the co-construction of shared inquiry structures in long-term knowledge building practices, we designed a timeline-based, inquiry-structuring platform: Idea Thread Mapper (ITM), which has been recently upgraded (Zhang et al., 2012; M.-H. Chen et al., 2013). The core functions focus on the needs to discover emerging interests and directions in students' 
interactive discourse, to formulate unfolding strands of inquiry through reflective processes, and to make such structures visible to support student ongoing reflection and participation. In line with dual-level construction, ITM includes (a) spaces and tools for online discourse interaction through which students generate deepening questions and ideas; and (b) features for inquiry structure creation and visualization to capture emerging inquiry directions and co-organize the online discourse accordingly. The online discourse space in ITM interoperates with Knowledge Forum (Scardamalia \& Bereiter, 2014) and potentially other platforms. Students contribute and build on one another's ideas in interactive discourse, with ideas presented in distributed postings (e.g., notes) and build-on responses. On top of the online discourse, the inquiry structure layer in ITM focuses on framing and mapping the unfolding strands of inquiry to address emergent objects of inquiry, tracing students' personal and collaborative roles, and documenting shared progress in each strand of inquiry over time to inform deeper future work. Table 2 summarizes the key features of ITM.

\section{Insert Table 2 about here}

Drawing upon the analytics developed in our prior work (Zhang et al., 2007), ITM organizes and visualizes each strand of inquiry as an "idea thread" (or "inquiry thread"). Each idea thread involves a sequence of discourse entries--possibly involving several build-on trees-that investigate a shared inquiry object (e.g., batteries) over a time period (see Figure 1). The closely related threads of inquiry further cluster into larger "wondering areas" in a complex knowledge building initiative.

Insert Figure 1 about here

Both idea threads and wondering areas are emergent structures, which are formed like 
"desire lines" in the collective knowledge space and reformed as the inquiry deepens and expands over time. In a knowledge building initiative, students begin with open exploration and discourse to develop initial ideas, questions, and research. Through monitoring emerging inquiry interests and evolving needs, they identify high-potential areas of inquiry and set up idea thread foci, within which they pursue joint inquiry to advance understandings while identifying deeper issues.

ITM includes analytics and tools to support these reflective efforts to identify, formulate, and adapt shared inquiry directions. Within each idea thread, the online notes and build-on responses are displayed on a timeline to make the temporal progress visible. Analytics show who is working on what thread(s) of inquiry over time. The contributors in each idea thread can coauthor a "Journey of Thinking" to deliberate their progress over time, including the goals/problems, "big ideas" learned so far, and deeper actions needed. At a higher level, the collective landscape of a whole inquiry is mapped out as clusters of idea threads that investigate interrelated issues through the contributions of all the members (see Figure 2). The map of idea threads further shows cross-thread connections, including build-on links among notes from different threads and connective "bridging contributions," each of which simultaneously investigates two or more topics as related issues. Analytics embedded in the map of idea threads provide feedback on the intensity and types of contributions made by different students over time. On top of the inquiry mapping for individual classrooms, a cross-classroom space was recently incorporated. For mutual learning and idea contact, students can view how other communities organize their inquiry in similar curriculum areas, access their "Journey of Thinking" syntheses as "boundary objects" (Zhang, Bogouslavsky, \& Yuan, 2017), and initiate cross-classroom "super talk" to discuss challenging issues. 
Insert Figure 2 about here

\section{A Design-Based Research Study}

Our team conducted multi-iteration design-based research to explore ITM-supported reflective processes to co-structure knowledge building practices in Grades 3-6 classrooms (J. Chen \& Zhang, 2016; M.-H. Chen, Zhang, \& Lee, 2013; Zhang et al., 2013, 2014). In each knowledge building initiative that investigated a core science topic over multiple months, students carried out various inquiry activities and participated in extended knowledge building discourse. With the support of ITM, students engaged in reflective conversations to co-define the focal areas and objects of inquiry as a community and organize interrelated strands of inquiry. They co-generated mapping of idea threads and "Journey of Thinking" to review knowledge progress and propose deeper actions. As the findings from the early iterations suggest, these reflective processes supported by ITM could help students develop a clearer awareness of their community's foci and progress in the whole inquiry. Their online discourse also became more connected with more interactive idea build-on and deeper questions. In order to further elaborate the process of reflective structuration and examine its impact on student knowledge building, this paper presents a new iteration of our design-based research.

\section{Method}

Research Design and Contexts. The study was conducted in two upper primary school classrooms at a K-6 school located in a major city in Canada. Each classroom had a mix of Grade 5 and 6 students ranging from 10 to 12 years old. There were 21 students in classroom A and 22 in classroom B. The two classes were taught by two experienced teachers, respectively, 
each having multiple years of experience with facilitating inquiry-based learning and knowledge building. Students in each classroom conducted collaborative inquiry about electricity over a 12week period, with two hours of science lessons each week. In line with principle-based designs, the whole inquiry unfolded as a continuous process without relying on pre-specified tasks and activities. For comparison, only classroom A implemented reflective structuration as an intentional, systematic effort that involved co-constructing shared structures of inquiry drawing upon existing ones and using the structures to monitor and guide the processes of inquiry. Table 3 provides an overview of the research questions, data analyses, and intended outcomes.

\section{Insert Table 3 about here}

Classroom implementation. In Week 1-3, both classrooms began their electricity inquiry with hands-on explorations. Students discussed their initial findings and shared their questions and ideas through a whole class conversation. Focusing on their questions, students conducted research using books, online materials, and experimental kits. Extending their face-toface interactions, students recorded their questions, ideas and experiment findings in Knowledge Forum for interactive online discourse.

In Week 4, classroom A conducted its first ITM reflection session to structure the collective foci and strands of inquiry. The major processes are summarized below (and elaborated in Results): (a) Individual reflection through which student wrote down interesting topics and questions of inquiry they had noticed in their collaborative discourse; (b) Whole class conversation to review the topics and questions and create a collective list of "juicy topics"; (c) Small group work to organize threads of inquiry using ITM; (d) Whole class reflective conversation to examine the map of all the idea threads (see Figure 1, before the first ITM 
session) and review the advances, cross-thread connections, and directions of further inquiry; and (e) Defining gaps of knowledge and deeper research needed in each area by writing a Journey of Thinking synthesis for each idea thread.

Based on the deeper questions proposed in the Journey of Thinking syntheses, the teacher recorded the major problems on a chart paper, suggesting what the community needed to research. As more in-depth work was conducted, students wrote new notes in Knowledge Forum. In Week 8, classroom A conducted its second ITM reflection session, in which students revisited the map of idea threads generated earlier and updated each idea thread by including new Knowledge Forum notes addressing deeper issues.

During the above period (Week 3-8), classroom B continued its inquiry and discourse without ITM-supported reflection. Students shared questions in Knowledge Forum and in the classroom. They then conducted research focusing on their questions using books, videos, and online materials; created models; and shared their findings in classroom discussions. Supporting their reflection and sharing of knowledge, students worked in groups to create posters focusing on their specific topics of research (e.g., batteries, conductors). In this process, students shared their work on Knowledge Forum and responded to one another's ideas and questions. In Week 9, classroom B implemented its only ITM-aided reflection session following the processes used by classroom A in its first ITM reflection session.

In the rest of the inquiry (Week 9-12), students in both classrooms concentrated on researching the identified issues and preparing culminating artifacts (e.g., presentations) to share their new knowledge as a whole class.

Analyses of classroom observations and videos. To address the first research question, we conducted qualitative analyses of the classroom observations and video records of the ITM 
reflection sessions and the follow-up interactions. This analysis was further supported by our notes from the monthly teacher meetings, organized to plan and reflect on the classroom inquiry. A research assistant observed each science lesson in the two classrooms and took detailed notes. ITM-supported reflection sessions and other major classroom activities (e.g., whole class discussions) were video-recorded. The videos were fully transcribed and analyzed using a narrative approach to video analysis (Derry et al., 2010). The construction of the narrative based on the videos and other data focused on capturing the reflective processes enacted by the actors (students and teacher) to appropriate, produce, use, and modify various collective structures to frame the shared objects and unfolding strands of inquiry. Two researchers first browsed the videos and transcriptions to develop an overall sense of the reflective processes, and then identified "digestible" chunks in the videos - major episodes of the reflective conversations by which students identified and negotiated high-potential "juicy topics" of inquiry, organized unfolding strands of inquiry and discourse, documented knowledge progress and gaps, and planned for deeper inquiries. These chunks of videos were analyzed to capture who (the actors) enacted what kinds of processes to develop what sorts of structures and related artifacts or resources (cf. Poole \& DeSanctis, 2004). The video episodes were further contextualized through building chronological links among the episodes to construct a storyline.

Analyses of the online interactions. The online discourse was a substantial component of the knowledge building processes and further provided a screen into which the classroom work (e.g., reading, experiments) was projected. We conducted both quantitative and qualitative analysis of student online discourse over the first eight weeks and compared the interaction patterns between classroom A and B. Two researchers first read the notes of each classroom in a chronological sequence to develop an overall sense of the online discourse in relation to the ITM 
reflection captured in the classroom videos. For quantitative analysis, we analyzed the frequencies of student note contributions and build-on connections. Content analysis (Chi, 1997) was conducted to code specific discourse moves. We applied a coding scheme that included four categories: questioning, explaining/theorizing, using evidence, and integrating and applying ideas. Questions were further coded based on fact-seeking (about factual information and definitions) vs. explanation-seeking (about reasons and mechanisms); and initial wondering (seeking general information about a topic) vs. idea-deepening questions (searching for deeper understanding on the basis of the existing information) (see Tao \& Zhang, in press; Zhang et al., 2007 for details). This coding scheme was tested by two coders, who independently coded 175 notes to assess inter-rater reliability, resulting in an agreement rate of $94.7 \%$ (Cohen's Kappa $=$ 0.94). Following the coding procedures tested, a primary coder coded each of the Knowledge Forum notes posted by the two classrooms.

Content analysis of student summaries of what they had learned. To assess student understanding of the electricity-related topics investigated by their community, we asked each student in classroom A and B to orally summarize what he/she had learned. The students first responded to a question asked by the researcher: "What are the important things you have learned about electricity?" They then elaborated their understandings of each of the topics mentioned, with the opportunity to go beyond their initial list of topics. Each student's summary was audio-recorded, transcribed, and coded through content analysis (Chi, 1997). Specifically, two researchers first read the online discourse and observation notes of the two classrooms to identify various topics of inquiry mentioned in relation to the topics specified in the curriculum guidelines. They shared the identified topics and merged similar or closely related topics (e.g., atoms and electrons), with a final list of 10 topical categories created (e.g., batteries, static 
electricity, voltage and charge, atoms). A primary coder then read each student's summary to identify utterances related to each of the topics. The ideas related to each topic were further coded based on epistemic complexity and scientific sophistication using coding schemes tested through our previous studies (see detailed coding frameworks and inter-rater reliability in Zhang et al., 2007, 2009). Scientific sophistication examines the extent to which students' ideas align with a scientific framework of electricity based on a four-point scale: 1 - pre-scientific, 2 - hybrid, 3 - basically scientific, and 4 - scientific. Epistemic complexity indicates students' efforts to produce not only descriptions of the material world, but also theoretical explanations and articulation of hidden mechanisms, which are central to the pursuit of science (Salmon, 1984). Focusing on epistemic complexity, a five-point scale (1- topical terms only, 2 - unelaborated facts, 3 - elaborated facts, 4 - unelaborated explanations, and 5 - elaborated explanations) was used to code ideas about each topic.

Beyond assessing student understanding of each topic, we analyzed the level of coherence in explaining the different topics about electricity. Borges and Horizonte (1999) identified increasingly complicated mental models used by students to explain how electricity works. These range from a general conception of electricity as the flow of energy to a more informed focus on positive and negative charges, a deeper explanation of the charges based on the movement of electrically charged particles, and the most complex understanding of electricity as a field phenomenon. Deeper conceptualizations favor more coherent understandings of seemingly different phenomena that share the same fundamental mechanisms. In light of these mental models of electricity, we created a coding scheme (Table 4) to categorize each student's explanations across the topics, such as electric circuits, conductors, batteries, current, and charges. Table 4 does not include electricity as a field phenomenon (category 4) 
because none of the students in this study showed this understanding; this depth of understanding is far beyond the expectation of elementary grades. Two raters independently coded 21 portfolio summaries using this coding scheme, resulting in an inter-rater agreement of 95.24\% (Cohen's Kappa $=0.97)$.

Insert Table 4 about here

\section{Results}

How did the community construct collective structures to frame the shared foci and

unfolding strands of inquiry? Through the narrative analysis of the classroom videos supported by our classroom observations and notes from the teacher meetings, we identified salient reflective processes by which classroom A co-constructed shared structures to guide and deepen its knowledge building work. These processes are elaborated below.

(a) Introducing electricity as the overarching area of inquiry. The science curriculum for Grade 5 and 6 includes electricity and several other scientific topics. At their planning meeting, the teachers considered these topics based on conceptual richness as well as the school's typical teaching schedule developed in the past few years, and selected electricity as the area of inquiry for the first part of the school year. In the first week, the teachers introduced electricity as the overarching area of inquiry. However, they did not specify what specific topics and questions their students should work on but encouraged students to define the inquiry directions based on their interests and questions. "Electricity study" became the name used to refer to this inquiry. An "Electricity" view was created in Knowledge Forum for each classroom as the online space for this inquiry.

(b) Individual ongoing noticing of potential objects of inquiry in various activities. Students 
engaged in an exploratory activity planned by the teacher. Students worked independently and in small groups to experiment with a range of materials including: batteries, wires, light bulbs, magnets and iron filings, balloons, and different types of fabric to explore static electricity. Questions were generated by the students based on their observations, such as: Why is hair attracted to the balloon after rubbing it against your hair? How is static electricity similar to regular electricity? Students took notes of their questions and ideas in their science notebooks. They researched their questions in the following week using books, websites, and experimental materials. They posted their ideas and questions in Knowledge Forum supported by the discourse scaffolds, such as using "I need to understand" as the sentence starter for a question. As reflected in their individual notebooks and online posts, students captured interesting issues to be investigated as they interacted with the electrical devices and phenomena in the hands-on exploration, encountered various scientific concepts (e.g., charge) in readings, and shared questions among their peers. The individual noticing and monitoring of potential inquiry objects as they arose from the community's ongoing work and discourse formed the foundation for coherent collective structures to emerge. In this process, the teacher did not predefine the objects of inquiry. Instead, he played out his influence by bringing certain experimental materials to the classroom, suggesting books and other readings to students, and participating in the classroom discussions to share interests in and ideas about certain topics. The electricity-related materials used in the classroom and noted in readings served to instantiate possible epistemic objects and directions to be investigated by the community.

(c) Framing and structuring knowledge building discourse around "juicy" objects of inquiry. By the end of the third week, students in classroom A had created 89 notes in their Knowledge Forum view. In Week 4, the whole class conducted a reflective conversation to review what was 
going on in their collective discourse. Different from regular classroom conversations focusing on specific questions and ideas, the reflective conversation focused on reviewing and organizing the community's collective work. With their Knowledge Forum view projected on a Smartboard, the teacher first contextualized the conversation by saying:

"We had some time to both work with materials and experiments and stuff, and work in the Knowledge Forum view. ... So, I had a look at it [Knowledge Forum view] over the last little while and found that it's enormous, and very, very complicated... What I was thinking we could do ... is to look at it and see what the major threads of ideas are. ... Can somebody notice? ... What's one big kind of "juicy topic" that's being talked about in the view?"

The teacher further shared his reflection on what topics may be considered as "juicy": "I don't mean just big [points to a big build-on tree in the view] like there are a lot of notes, but they might be important, juicy topics. " Students responded to propose various topics discussed. They first identified specific narrow topics, such as notes mentioning batteries made with lemons. The teacher encouraged students to further frame the conceptual focus related to electricity, by asking: "What are these notes about?" Students reframed their posts about their experiments with lemon juice as "how batteries work," and as a potential "juicy topic" of inquiry. Continuing the reflection modeled as a whole class, each student then worked with a partner to conduct a more careful review of potential "juicy topics" addressed in the online discourse space. Each group (dyad) was given a printout of the Knowledge Forum notes, discussed what had been investigated, and circled clusters of notes discussing different topics using color markers. The whole class then reconvened to share the topics identified, with the teacher recording the topics 
on a board. A total of ten topics were recorded, including batteries, static electricity, magnets, voltage and charge, energy sources, Leyden jar, atoms, electrons, positive/negative, and light. The teacher facilitated further reflective talks among students to clarify the deeper electrical processes and objects under some of the specific topics.

Teacher (T): Okay, this is a pretty good list. Are there any of these...that probably just fit exactly together and we probably don't need two different categories for?

S1: Positive/negative and electrons.

T: Positive/negative and electrons. OK. [draws an arrowed line between these two topics on the board] Any other ideas...?

S2: Leyden jar and static electricity.

S3: Yeah.

T: Leyden jar and static electricity. Might be part of the same thing? [draws an arrowed line between these two topics on the board] Like that? Did some people put Leyden jar under static electricity?

Several students talk together: Yeah.

T: OK....So we have eight main threads.

Based on the eight "juicy topics" identified, students used ITM to organize and review their online discourse related to each object as an idea thread. The teacher explained the purpose of ITM was to help the whole community to organize its inquiry progress related to the "juicy topics." He then modeled the use of ITM to go through an initial pass to construct one idea thread, as an example. The teacher then asked students to each select a topic for which they 
would organize an idea thread in ITM. Eight temporary small-groups were formed to construct idea threads for the eight "juicy topics" of inquiry (with one of the groups working on the example idea thread started by the teacher). Focusing on each focal topic, group members first discussed what key terms should be used to search for Knowledge Forum notes related to their topic written by their class members. They reviewed the notes and selected those that contributed important understandings. ITM displayed the selected notes on a timeline as an idea thread and further retrieved authors involved in this line of work, with options to show build-on connections over time (see Figure 2).

(d) Using the map of idea threads as a structure to monitor collective knowledge work and deliberate deepening goals and activities. Around the end of the first ITM reflection session, the teacher mapped out the eight idea threads on the same timeline (see notes before the first ITM session in Figure 1) and facilitated a reflective conversation about the inquiry progress and directions.

Teacher (T): ...we can see the map [points to the map of the eight idea threads on the screen] of all the things we're thinking about. So take a look and tell me what you notice... So the lines that have gone all the way through are the ones that we've been talking about all of the time. The ones that started and stopped are ones that we've been doing for some smaller portion of time. It also tells you the amount of notes there are. There are 33 notes related to voltage and charge in some way, which is kind of interesting. S1, what do you notice?

S1: That atoms didn't really start to come up because $\mathrm{N}$ (an invited speaker) did that lesson about positive and negative and to help us find out about batteries, and 
then ...you (the teacher) started to talk about atoms so it wasn't at the beginning. T: Yeah,... this [note] about atoms came up later. What's one that someone else noticed, either about the number of notes or which ones have been going for a long time...

S2: Static electricity has been going on for the longest time...but it has one of the least notes.

T: Yeah, it doesn't have a ton of notes in it, right? ... Now you have like a bunch of different threads with a bunch of different ideas that you can work on, what do you think would be a really good use of your time? So if you said, OK, I've got to work on one of these, what would you work on?

S4: The one with the least amount of notes...Either light... or magnets.

In the above excerpt, members reflected on how the different idea thread topics emerged and reviewed the intensity, quality, and timespan of the contributions in each idea thread. They pointed out threads that had few notes or needed more solid contributions, and proposed further actions in these areas. Threads with very few authors were also evident in the map view of idea threads, informing potential opportunities for students to expand their participation and connections with their peers to make needed advances.

In the next two weeks, students volunteered to do deeper research in the needed areas as related to their personal interests. Students working on each thread topic co-authored a Journey of Thinking synthesis to summarize the "big ideas" learned, focal problems to be further addressed, and specific actions to be taken. For example, reviewing the thread about magnets that included eight notes by ten authors by the time of the first ITM reflection, two students co- 
created the Journey of Thinking synthesis shown in Table 5, highlighting "big ideas" learned as well as core problems to be addressed through further actions of inquiry. The Journey of Thinking syntheses written for the different threads of inquiry were transferred to a big chart paper, which was hung on a wall in the classroom to highlight the "big ideas" and problems to the awareness of the whole class.

\section{Insert Table 5 about here}

(e) Re-framing and reorganizing the idea threads based on new inquiry progress. To address the weak areas and deep problems, students conducted individual and collaborative research using a set of books, videos, websites, and experimental materials. They shared their new ideas and questions in their face-to-face and online discourse. For example, in a whole-class discussion in Week 6, students shared their summaries of the "big ideas" learned about each theme. Reflecting on the ideas shared, students revisited the eight "juicy" inquiry objects and their connections to organize what their community was working on.

S1: Magnets go to electrons and...static [electricity] makes voltage and charge, and that makes energy. When you rub it, the fur is charging up the rod and it's all "electron-y" and that means the fur is positive. When we create an electrical charge by putting electrons on something, or taking electrons away from something, we get static electricity.

S2: I think that maybe everything is related to each other. Once we learn more, we might see how all these threads relate to each other.

S3: When you put your finger on Leyden jar (when studying static electricity), it 
sparks. A huge number of electrons rush to your finger. If you took a whole lot of electrons together, all pressed together, they look like the spark...

S4: Everything is connected, so they are all the same thing: electrons are part of atoms and electrons have charge, and so charge is connected to atoms through electrons.... All are connected... Chain ends at atoms every time because atoms are everything and everything is made up of atoms. It is the essence...It all comes back to atoms and understanding how atoms work.

The teacher participated in this discussion by asking for more detailed thoughts about the nature of the connections and taking visual notes on the Smartboard to keep track of the connections identified. Figure 3 shows the visual created. Instead of a simple list of eight inquiry topics, the community reframed the focus of the knowledge building work as an interconnected web of inquiry objects to be understood as a whole, suggesting opportunities for conceptual and social connections.

\section{Insert Figure 3 about here}

This insight in cross-thread connections was also reflected in the Journey of Thinking syntheses composed by student groups. When synthesizing "big ideas" in each idea thread, students mentioned electron movement in six out of the eight idea threads: "Everything is made of atoms. The atoms are made out of protons, neutrons, and electrons." "Electrons have a negative charge. It's always electrons that transfer onto your body when you rub your foot on the carpet." "Electrons moving create energy."

In the subsequent classroom discussions, the visual of the interconnected inquiry topics was displayed on the Smartboard to focus and guide student interactions. As advances were 
made, students in classroom A continued their knowledge building discourse online. In Week 8, they conducted another ITM reflection session in which they reviewed the idea threads organized about four weeks ago and updated each thread by adding the new relevant contributions (see Figure 1 for notes added after the first ITM session). For example, the idea thread on magnets was extended from eight notes by ten authors by the first ITM reflection to 18 notes by 14 authors.

Students in classroom B engaged in a similar set of knowledge building activities to investigate their questions about electricity and share their questions and ideas on Knowledge Forum. Their online discourse addressed a wide range of issues, which were not systematically reviewed until Week 9 in late November. The teacher in classroom B facilitated an ITMsupported reflection session following the processes used by classroom A in its first ITM reflection session. As the video recordings and classroom observation notes revealed, the teacher first contextualized the reflective conversation by showing the Knowledge Forum view with over 150 notes, highlighting the need to review what the students were researching: to reconnect the notes "with some things that you were wondering about" and with "juicy" and "big" topics. Students responded to share their thoughts about what a "juicy" and "big" topic looked like. They then worked in temporary small groups to review the printout of their Knowledge Forum view and color-code notes addressing various possible "juicy topics." The topics identified were shared through a whole class discussion, leading to the formulation of eight "juicy topics" as the collective focus of classroom B, including atoms, batteries, circuits, conductors, static electricity, current, electric flow, and sources of power. Students further worked in small groups to identify contributive Knowledge Forum notes for each topic, and wrote a Journey of Thinking synthesis for each idea thread to highlight knowledge progress and deeper questions. However, because 
the idea threads and syntheses were created near the end of the electricity unit, classroom B did not get the chance to use these artifacts to systematically guide deeper research.

\section{In what ways did reflective structuration with ITM enhance the knowledge building}

interaction? We analyzed the online knowledge building discourse of the two classrooms during the first eight weeks when only classroom A implemented reflective structuration. We first compared the online discourse of the two classrooms based on two quantitative measures: the number of notes contributed by each student and the percentage of notes with build-on links. Each student contributed an average number of 8.30 notes $(S D=4.56)$ in classroom $\mathrm{A}$ and 4.60 notes $(S D=2.12)$ in classroom $\mathrm{B}$, with a significant difference $(t=3.4379, d f=41, p<.01)$. Among the notes posted, $37.60 \%$ of classroom A's notes and $33.20 \%$ of classroom B's notes had build-on links. Students in classroom A made more active and connected contributions.

To further examine the specific discourse moves, we conducted content analysis of the online discourse focusing on the nature of their questions and specific moves to address the questions. As Table 6 shows, classroom A had a higher proportion of notes raising questions than classroom B. More specifically, classroom A had a higher percentage of notes asking explanation-seeking questions (e.g., why, how) as opposed to fact-seeking questions, and ideadeepening questions in search of deeper understanding (e.g., Why does the static charge not work well at high levels of humidity?) as opposed to initial wondering questions (e.g., how does static electricity work?). In both classrooms, a majority of the notes contributed personal explanations to address the various questions. Classroom A had a lower proportion of notes sharing personal explanations than classroom B but had a higher proportion of notes using evidence to back up their explanations and integrating ideas to solve problems and understand cross-theme connections. As an example of the cross-theme connections, a student in classroom 
A wrote: "Electrons are the essence of charge. Atoms are the root of everything having to do with electricity."

\section{Insert Table 6 about here}

Deepening the quantitative analysis, we qualitatively traced the online discourse moves in each idea thread in connection with the community's "juicy topics." As a compelling pattern, the focus of students' posts evolved from concrete toward more conceptual objects to search for underlying mechanisms, which brought forth deep connections across the different threads of discourse. As noted earlier, the whole inquiry initiative began with students' hands-on exploration of batteries, light bulbs, magnets, and static electricity. Students' initial online discourse focused on sharing their observations and questions, serving as the starters of the idea threads about batteries, static electricity, energy sources, and magnets (see Figure 1). Sustaining inquiry in these idea threads, students searched for conceptual explanations of the empirical facts that they had observed. More abstract concepts (e.g., electric charges, electrons, and atoms) emerged and became the objects of inquiry in their own right, leading to the emergence of new threads of inquiry focusing on these objects. For example, students' online discourse on fabrics that cause static electricity gave rise to the concepts of negative and positive charges. Interest thus emerged among the students to study positive and negative charges, electrons, and atomic structure. In the first ITM reflection, students explicitly identified such abstract concepts as electric charges and voltage, atoms, and electrons as core topics of inquiry. They further formulated deeper explanation-seeking questions about electrons and electric charges in the Journey of Thinking syntheses regarding these topics, such as: What makes electrons move? What is the connection between atoms and energy? These objects and questions of inquiry 
became the focus of the subsequent work. As Figure 1 shows, the idea threads about charges/voltage, atoms, and electrons involved the most intensive discourse after the first ITM reflection in mid-October.

Using the analytics embedded in ITM, we further examined how the discourse in the different idea threads was connected through the "bridging notes," each of which simultaneously talked about two or more interrelated topics of inquiry to discuss interrelated issues. The bridging notes shared between the different idea threads were marked using vertical dashed lines in the idea thread map shown in Figure 1. For example, on November 8, a note about lightning was created in two idea threads: Light and Voltage and Charge, explaining lightning based on positive and negative electric charges. As expected, classroom A had more cross-thread connections than classroom B (see Figure 4).

Insert Figure 4 about here

\section{In what ways did reflective structuration enhance student understandings? This}

question was addressed through the content analysis of student personal summaries of what they had learned about electricity (before classroom B's ITM reflection). The coding scheme captured the number of content topics addressed, the scientific quality (from pre-scientific to scientific) of ideas related to each topic, the epistemic complexity of ideas (from unelaborated facts to elaborated explanations), and the mental models based on which students explained electricity (see Table 4). On average, students in classroom A summarized more inquiry topics about electricity $(M=5.89, S D=1.63)$ than those in classroom B $(M=4.65, S D=1.18)(F(1.37)=7.51$, $p=.009)$. Specifically, classroom A had many more students summarizing understandings of abstract topics such as electrical charges and atoms and electrons. The average scientific rating 
of students" ideas in both classrooms was between "3 - basically scientific" and "4 - scientific" without significant difference $(p>.05)$. Students in classroom A articulated understandings of the various topics at a higher level of epistemic complexity $(M=3.94, S D=.58)$ than those in classroom B $(M=3.49, S D=.53)(F(1,36)=6.51, p=.015)$, showing explanations of mechanisms, processes, reasons, and relationships.

Student ideas about the different electricity topics were further coded as a whole to gauge their primary notions (mental models) about how electricity works. Figure 5 shows the proportions of students giving different explanations, with a significant difference between the two classrooms $\left(X^{2}=16.03, d f=3, p=.001\right)$. Classroom A had a higher percentage of students giving more advanced explanations conceiving electricity as negative and positive charges (category 2) carried by electrically charged particles (category 3). On the contrary, a majority of students in classroom B explained electricity at a general level based on energy flow from the battery to the light bulb (category 1 ).

Insert Figure 5 about here

\section{Discussion}

In the theory section of the paper, we introduced reflective structuration with three main points. Further details on the theory are summarized in Table 1. Then in the technology section, we described the ITM design that supports the theory. The key design features are highlighted in Table 2. Now we will review how the results of the data analysis elaborate the three main points of the theory as scaffolded in the classroom by the technology.

\section{(a) Members in a community can co-construct inquiry structures as they build domain}

\section{knowledge.}


The findings demonstrate that the fifth- and sixth-graders were able to work with their teacher to construct collective inquiry structures as they carried out joint efforts to build and deepen their knowledge. The co-construction of the inquiry structures was achieved through students' reflective efforts facilitated by their teacher. On an ongoing basis, students in classroom A engaged in personal reflective monitoring of the emergent inquiry objects, progress, and directions. They further conducted reflective conversations about what they were researching, through what contributions, and with what connections. As the qualitative analysis of classroom videos and artifacts showed, the reflective conversations supported the bottom-up emergence of structures as a community and the reflective use of the structures by the teacher and students: formulating shared objects of inquiry that rose above student questions and interests, organizing members' contributions to each area as an idea thread; and, then, using the map of idea threads to monitor the community's ongoing work and guide personal participation and collaboration. This process led to the elaboration/adaptation of collective inquiry structures, as an emergent communal outcome. The structures were reified using structure-bearing artifacts such as the map of idea threads and the visualization of the cross-thread connections.

\section{(b) There is a temporal interplay between the two layers of construction.}

Classroom A appropriated structures from the school's context to focus and guide members' initial exploratory inquiry actions and interactions, which gave rise to further structural elaboration and adaptation as the inquiry unfolded in the next few weeks. The updated structures served to capture emergent directions and connections in the community and support members' deeper inquiry efforts. With such support, students in classroom A engaged in more productive knowledge building. They had a higher proportion of notes identifying explanationseeking and idea-deepening questions, using evidence to examine explanations, and integrating 
and applying related ideas to address challenging issues (Table 6). The structures to frame shared goals and cross-thread connections enabled more connected discourse (Figure 4). The enhancement to the inquiry process also led to improved outcomes: students in classroom A demonstrated more complicated understandings of a broad range of issues about electricity (see Figure 5). These findings are consistent with the results of a recent study (Tao \& Zhang, in press) conducted in a fifth-grade classroom. The students co-constructed process-focused structures in the form of "research cycles" to guide their sustained inquiry, with a positive impact on their knowledge advances.

\section{(c) Co-constructing inquiry structures serves as a means to fostering student agency and} collective responsibility.

Students took on high-level responsibilities as they engaged in the reflective conversations to formulate shared goals around the "juicy topics," organized their community's unfolding threads of inquiry, and delineated their inquiry agenda through the Journey of Thinking documentations. The co-constructed structures then became a resource used by students to direct their deeper inquiry, ongoing interaction, and reflection on progress, fostering intentional and connected efforts for knowledge building.

With the co-constructed structures mediating the community's work, traditional roles of the teacher to coordinate and orchestrate classroom processes can be largely distributed to the community, which enacts collective control with the teacher's critical input. As noted in the results, the teacher in classroom A played important roles in the co-construction and reflective use of the collective structures. These included: (a) mediating the appropriation of overarching inquiry area from the school's curriculum, (b) seeding potential objects and directions of inquiry through learning materials and activities, (c) facilitating and modeling reflective conversations to 
frame "juicy topics" as core objects of inquiry and organize idea threads, (d) capturing and reifying the structures emerged using online and classroom artifacts, and (e) ongoing referencing of the structure-bearing artifacts in the classroom to support student participation in knowledge building and reflection on progress.

\section{Limitations}

The findings need to be interpreted with a number of limitations in mind. First, the analysis of the reflective processes to co-construct collective structures was primarily focused on whole class reflective conversations without detailing the reflective processes undertaken by individuals and small groups. Second, the examination of the impact of reflective structuration was based on the comparisons between two classrooms taught by two teachers. The teachers both had experience with inquiry-based learning and knowledge building and their students had use Knowledge Forum in the past. However, we could not exclude other possible variations between the two classrooms, such as the teachers' specific teaching styles and student characteristics that were not analyzed in this study. Future research needs to conduct deeper analyses of the process and impact of reflective structuration in broad classroom settings, and to test how the co-construction of inquiry structures may help new teachers to get started with knowledge building and work with student-driven knowledge processes productively.

\section{Conclusions and Implications}

This research was intended to address the challenge of how student-driven, ever-deepening inquiry processes may become socially organized and supported in a way that engages student epistemic agency. The results elaborated a reflective structuration approach to co-organizing the collective journey of inquiry through constructing shared inquiry structures over time based on emergent directions. As the findings suggest, students, as young as fifth- and sixth-graders, can 
engage in dual-level construction to construct/reconstruct shared inquiry structures as a community as they build knowledge in a domain area. With their teacher's input and support, students construct and elaborate such structures through a temporal process as they reflect on their undergoing work in connection with their past progress and passible future opportunities. The temporal dimension of structure building is essential. Students reflect on the time dimension of their knowledge building, supported by ITM, and thereby can frame/reframe their unfolding inquiry practices in response to emerging directions. This reflective process can be used to shift the control over inquiry from the teacher's initial inputs to student agency. The culmination of the shift in agency enables student ownership over their collective journey of thinking. This brings about new classroom dynamics that are different from pre-scripted inquiry and collaboration. The inquiry structures in a community are progressively generated and elaborated in light of the evolving knowledge of the community, informing ever-deepening opportunities for members' productive actions and interactions.

As the implications to researchers, this research sheds light on a new way to sustain longterm collective inquiry and knowledge building that engages students' high-level agency. We have introduced the idea that co-constructing shared inquiry structures over time is key to sustaining student-driven, dynamic knowledge practices. The co-constructed structures build upon existing structures and further respond to emergent changes (“desire lines") in members' knowledge building interactions to chart the ever-deepening courses of inquiry and collaboration. Attending to the reflective and emergent process of structure development may help the field reconceptualize the tension between guiding structures and student agency in collective inquiry and knowledge building. Co-constructed structures can simultaneously address the two oftencompeting needs to guide the inquiry processes while fostering students' high-level 
responsibility.

As for the implications to educational practitioners, this research offers a new way to implement collective inquiry and knowledge building to transform classroom practices. In an inquiry-based initiative (unit) that may extend over multiple weeks or months, the teacher can work with his/her students to co-structure their collective journey of inquiry without extensive scripting. High-level issues, such as what to learn/investigate, through what processes, by whom, can be co-structured by students with the teacher as the inquiry proceeds over time (see Table 1). This approach will challenge traditional practices of lesson planning that focus on pre-defining learning goals and sequencing activities. To ease teacher implementation, we are creating classroom-oriented materials and tools to support the reflective structuration process, including tools to support the teacher's open planning and ongoing noticing (observation) and ways to organize reflective classroom meetings to co-structure deepening inquiry.

This research also suggests opportunities to advance online environments and analytics for collaborative learning and knowledge building. ITM showcases possible designs to incorporate a meta-layer of emergent inquiry structures in collaborative learning environments that make the collective landscape and unfolding directions of inquiry visible in a community. In light of the research findings, our team has created an upgraded version of ITM, which includes (a) new visualizations for students to co-organize inquiry areas and idea threads and position their collaborative roles, (b) analytics to detect emergent inquiry directions and progress to support idea thread review and organization, and (c) cross-community interaction for students to share their Journey of Thinking syntheses with other classrooms that study the related topics for mutual learning and build-on (Zhang et al, 2017). We hope that these conceptual and technological advances will contribute to the efforts of the larger field to transform classrooms 
into sustainable and interconnected knowledge building communities.

\section{Acknowledgments}

This research was sponsored by the U.S. National Science Foundation (IIS \#1122573, IIS \#1441479). We owe special thanks to the teachers and students for their creative work enabling this research; and to our team members for their contributions to the software development, classroom research, and data analysis. We extend our gratitude to Allan Collins, Janette Pelletier, Carolyn Rosé, Keith Sawyer, Marlene Scardamalia, and Gerry Stahl for their input and support; and to the journal editors and anonymous reviewers for their insightful comments and suggestions.

\section{References}

Archer, M. S. (1982). Morphogenesis versus structuration: On combining structure and action. British Journal of Sociology, 33, 455-483.

Archer, M. S. (1995). Realist social theory: The morphogenetic approach. Cambridge: Cambridge University Press.

Bell, P., \& Linn, M. C. (2000). Scientific arguments as learning artifacts: Designing for learning from the web with KIE. International Journal of Science Education, 22, 797-817.

Bereiter, C., Cress, U., Fischer, F., Hakkarainen, K., Scardamalia, M., \& Vogel, F. (2017). Scripted and unscripted aspects of creative work with knowledge. In B. K. Smith, M. Borge, E. Mercier, and K. Y. Lim (Eds.), Making a difference: Prioritizing equity and access in CSCL, $12^{\text {th }}$ International Conference on Computer Supported Collaborative Learning (CSCL2017) (Volume 2, pp.751-757). Philadelphia, PA: International Society of the Learning Sciences. 
Bielaczyc, K., \& Collins, A. (2006). Fostering knowledge-creating communities. In A. M. O’Donnell, C. E. Hmelo, Silver, \& G. Erkens (Eds.), Collaborative learning, reasoning, and technology (pp.37-60). Mahwah, NJ: Erlbaum.

Borges, A. T., \& Horizonte, B. (1999). Mental models of electricity. International Journal of Science Education, 21, 95-117.

Brown, A. L., \& Campione, J. C. (1996). Psychological theory and the design of innovative learning environments: On procedures, principles, and systems. In L. Schauble \& R. Glaser (Eds.), Innovations in learning: New environments for education (pp. 289-325). Hillsdale, NJ: Lawrence Erlbaum Associates.

Chen, B., \& Hong, H.-Y. (2016). Schools as knowledge-building organizations: Thirty years of design research. Educational Psychologist, 51, 266-288.

Chen, J., \& Zhang. J. (2016). Design Collaborative Formative Assessment for Sustained Knowledge Building. In C.-K. Looi, J. Polman, U. Cress, \& P. Reimann (Eds.), Transforming Learning, Empowering Learners: Proceedings of the International Conference of the Learning Sciences (Vol. 1) (pp.647-654). Singapore: International Society of the Learning Sciences.

Chen, M.-H., Zhang, J. \& Lee, J. (2013). Making collective progress visible for sustained knowledge building. In N. Rummel, M., Kapur, M. Nathan, \& S. Puntambekar (Eds.), To See the World and a Grain of Sand: Learning across Levels of Space, Time, and Scale: CSCL 2013 Conference Proceedings Volume 1 (pp.81-88). International Society of the Learning Sciences.

Chi, M. T. H. (1997). Quantifying qualitative analyses of verbal data: A practical guide. Journal of the Learning Sciences, 6, 271-315. 
Chuy, M., Zhang, J., Resendes, M., Scardamalia, M., \& Bereiter, C. (2011). Does contributing to a knowledge building dialogue lead to individual advancement of knowledge? In $\mathrm{H}$. Spada, G. Stahl, N. Miyake, \& N. Law (Eds.), Connecting computer-supported collaborative learning to policy and practice (Volume I, pp. 57-63). Hong Kong: International Society of the Learning Sciences.

Damşa, C. I. (2014). The multi-layered nature of small-group learning: Productive interactions in object-oriented collaboration. International Journal of Computer-Supported Collaborative Learning, 9, 247-281.

Derry, S. J., Pea, R. D., Barron, B., Engle, R.A., Erickson, F. Goldman, R.,.. Sherin, B. L. (2010). Conducting video research in the learning sciences. Journal of the Learning Sciences, 19, 3-53.

Dillenbourg, P., Järvelä, S., \& Fischer, F. (2009). The evolution of research in computersupported collaborative learning: from design to orchestration. In N. Balacheff, S. Ludvigsen, T. de Jong, A. Lazonder, and S. Barnes (Eds.), Technology-Enhanced Learning (pp. 3-19). New York, NY: Springer.

Engeström, Y. (2008). From teams to knots: Activity-theoretical studies of collaboration and learning at work. New York, NY: Cambridge University Press.

Fischer, F., Kollar, I., Stegmann, K., \& Wecker, C. (2013). Toward a script theory of guidance in computer-supported collaborative learning. Educational Psychologist, 48, 56-66.

Giddens, A. (1984). The constitution of society. Cambridge, Oxford: Polity Press.

Gloor, P. A. (2006). Swarm creativity: Competitive advantage through collaborative innovation networks. Oxford, UK: Oxford University Press

Hakkarainen, K. (2003). Progressive inquiry in a computer-supported biology class. Journal of 
Research in Science Teaching, 40(10), 1072-1088.

Hakkarainen, K. (2009). A knowledge-practice perspective on technology-mediated learning. International Journal of Computer-Supported Collaborative Learning, 4, 213231.

Hannafin, M. J., Land, S., \& Oliver, K. M. (1999). Open learning environments: Foundations, methods, and models. In C. Reigeluth (Ed.), Instructional design theories and models (pp. 115-140). Mahwah, NJ: Lawrence Erlbaum Associates.

Hewitt, J. (2001). Beyond threaded discourse. International Journal of Educational Telecommunications, 7(3), 207-221.

Hmelo-Silver, C. (2003). Analyzing collaborative knowledge construction: Multiple methods for integrated understanding. Computers \& Education, 41(4), 397-420.

Hmelo-Silver, C. (2004). Problem-based learning: What and how do students learn? Education Psychology Review, 16(3), 235-266.

Järvelä, S., \& Hadwin, A. F. (2013). New frontiers: regulating learning in CSCL. Educational Psychologist, 48(1), 25-39.

Johnson, S. (2001). Emergence: The connected lives of ants, brains, cities. New York, NY: Scribner.

Kirschner, P. A., \& Erkens, G. (2013). Toward a framework for CSCL research. Educational Psychologist, 48 (1), 1-8.

Knorr Cetina, K. (2001). Objectual practice. In T. R. Schatzki, K. Knorr Cetina \& E. Savigny (Eds.), The practice turn in contemporary theory (pp.175-188). London: Routledge. Mercer, N., \& Littleton, K. (2007). Dialogue and the development of children's thinking. London: Routledge. 
Miettinen, R., \& Virkkunen, J. (2005). Epistemic objects, artefacts and organizational change. Organization, 12(3), 437-456.

National Research Council. (2012). A framework for K-12 science education: Practices, crosscutting concepts, and core ideas. Washington, D.C.: The National Academies Press.

NGSS Lead States. (2013). Next Generation Science Standards: For states, by states. Washington, DC: The National Academies Press.

O’Neill, D. K. (2016). When form follows fantasy: Lessons for learning scientists from modernist architecture and urban planning. Journal of the Learning Sciences, 25, 133-152.

Poole, M. S., \& DeSanctis, G. (1992). Microlevel structuration in computer-supported group decision making. Human Communication Research, 19(1), 5-49.

Poole, M. S., \& DeSanctis, G. (2004). Structuration theory in information systems research: Methods and controversies. In M. E. Whitman \& A. Woszcynski (Eds.), Handbook of Information Systems Research (pp. 206-249). Hershey, PA: Idea Group.

Rogat, T.K., \& Linnenbrink-Garcia, L. (2011). Socially shared regulation in collaborative groups: An analysis of the interplay between quality of social regulation and group processes. Cognition and Instruction, 29, 375-415.

Roschelle, J. (1992). Learning by collaborating: Convergent conceptual change. Journal of the Learning Sciences, 2, 235-276.

Salmon, W. C. (1984). Scientific explanation and the causal structure of the world. Princeton, NJ: Princeton University Press.

Sawyer, R. K. (2004). Creative teaching: Collaborative discussion as disciplined improvisation. Educational Researcher, 33(2), 12-20.

Sawyer, R. K. (2005). Social emergence: Societies as complex systems. New York, NY: 
Cambridge University Press.

Sawyer, R. K. (2007). Group genius: The creative power of collaboration. New York: Basic Books.

Scardamalia, M. (2002). Collective cognitive responsibility for the advancement of knowledge. In B. Smith (Ed.), Liberal education in a knowledge society (pp. 67-98). Chicago, IL: Open Court.

Scardamalia, M., \& Bereiter, C. (2014). Knowledge building and knowledge creation: Theory, pedagogy, and technology. In R. K. Sawyer (Ed.), The Cambridge handbook of the learning sciences $\left(2^{\text {nd }}\right.$ Ed, pp. 397-417). New York: Cambridge University Press.

Sewell, W. H. Jr. (1992). A theory of structure: Duality, agency, and transformation. American Journal of Sociology, 98(1), 1-29.

Slotta, J., Suthers, D., \& Roschelle, J. (2014). CIRCL Primer: Collective Inquiry and Knowledge Building. In CIRCL Primer Series. Retrieved from http://circlcenter.org/collectiveinquiry-knowledge-building/

Stahl, G., \& Hesse, F. (2009). Classical dialogs in CSCL. International Journal of ComputerSupported Learning, 4(3), 233-237.

Stahl, G., Koschmann, T., \& Suthers, D. (2014). Computer-supported collaborative learning. In R. K. Sawyer (Ed.), The Cambridge handbook of the learning sciences $\left(2^{\text {nd }}\right.$ Ed, pp. 517538). New York: Cambridge University Press.

Suthers, D. D., Vatrapu, R., Medina, R., Joseph, S., \& Dwyer, N. (2008). Beyond threaded discussion: Representational guidance in asynchronous collaborative learning environments. Computers \& Education, 50, 1103-1127.

Tabak, I., \& Baumgartner, E. (2004). The teacher as partner: Exploring participant structure, 
asymmetry, and identity work in scaffolding. Cognition and Instruction, 22, 393-429.

Tao, D., \& Zhang, J. (in press). Forming shared inquiry structures to support knowledge building in a Grade 5 community. Instructional Science.

Tao, D., Zhang, J., \& Gao, D. (2017). Reflective structuration of knowledge building practices in Grade 5 science: A two-year design-based research. In Smith, B. K., Borge, M., Mercier, E., and Lim, K. Y. (Eds.), Making a Difference: Prioritizing Equity and Access in CSCL, 12th International Conference on Computer Supported Collaborative Learning (CSCL) 2017, Volume 2. Philadelphia, PA: International Society of the Learning Sciences. Tao, D., Zhang, J., \& Huang, Y. (2015). How did a grade 5 community formulate progressive, collective goals to sustain knowledge building over a whole school year? In O. Lindwall \& S. Ludvigsen (Eds.), Exploring the material conditions of learning: Proceedings of the 11th International Conference on Computer Supported Collaborative Learning (Vol. 1, pp. 419-426). Gothenburg, Sweden: International Society of the Learning Sciences.

van Aalst, J. (2009). Distinguishing knowledge-sharing, knowledge-construction, and knowledge-creation discourses. International Journal of Computer-Supported Collaborative Learning, 4, 259-287.

van Aalst, J. \& Chan, C. K. K. (2007). Student-directed assessment of knowledge building using electronic portfolios. The Journal of the Learning Sciences, 16, 175-220.

Williams, W. M., \& Yang, L. T. (1999). Organizational creativity. In R. J. Sternberg (Ed.), Handbook of creativity (pp. 373-391). Cambridge, UK: Cambridge University Press Zhang, J. (2009). Comments on Greenhow, Robelia, and Hughes: Toward a creative social Web for learners and teachers. Educational Researcher, 38, 274-279.

Zhang, J. (April, 2013). Foster a self-sustained, collective trajectory of inquiry through adaptive 
collaboration. Paper presented at the Annual Meeting of American Educational Research Association, San Francisco, CA.

Zhang, J., Chen, M. -C., Li, H., Zhao, Y., Chen, J., Rajbhandari, B. L., ... \& Naqvi, S. (August 2012). Making collective progress visible: The design and application of Idea Thread Mapper for sustained knowledge building. Knowledge Building Summer Institute, Toronto, ON, Canada.

Zhang, J., \& Messina, R. (2010). Collaborative productivity as self-sustaining processes in a Grade 4 knowledge building community. In K. Gomez, J. Radinsky, \& L. Lyons (Eds.), Proceedings of the 9th International Conference of the Learning Sciences (pp. 49-56). Chicago, IL: International Society of the Learning Sciences.

Zhang, J., Bogouslavsky, M., \& Yuan, G. (2017). Cross-community interaction for knowledge building in two Grade 5/6 classrooms. In Smith, B. K., Borge, M., Mercier, E., and Lim, K. Y. (Eds.), Making a Difference: Prioritizing Equity and Access in CSCL, 12th International Conference on Computer Supported Collaborative Learning (CSCL) 2017 (Vol. 1). Philadelphia, PA: International Society of the Learning Sciences.

Zhang, J., Chen, M.-H., Chen, J., \& Mico, T.F. (2013). Computer-supported metadiscourse to foster collective progress in knowledge-building communities. In N. Rummel, M., Kapur, M. Nathan, \& S. Puntambekar (Eds.), To See the World and a Grain of Sand: Learning across Levels of Space, Time, and Scale: CSCL 2013 Conference Proceedings Volume 2 (pp.197-200). International Society of the Learning Sciences.

Zhang, J., Hong, H.-Y., Scardamalia, M., Teo, C., \& Morley, E. (2011). Sustaining knowledge building as a principle-based innovation at an elementary school. Journal of the Learning Sciences, 20, 262-307. 
Zhang, J., Lee, J., \& Chen, J. (2014). Deepening inquiry about human body systems through computer-supported metadiscourse. Paper presented at the Annual Meeting of American Educational Research Association, Philadelphia, PA.

Zhang, J., Scardamalia, M., Lamon, M., Messina, R., \& Reeve, R. (2007). Socio-cognitive dynamics of knowledge building in the work of nine- and ten-year-olds. Educational Technology Research and Development, 55, 117-145.

Zhang, J., Scardamalia, M., Reeve, R., \& Messina, R. (2009). Designs for collective cognitive responsibility in knowledge building communities. Journal of the Learning Sciences, 18, $7-44$. 


\section{Figures}

\section{Update Idea Thread: Electrons \\ Project: Electricity Gr5/6)

\begin{tabular}{|l|l|l|l|l|l|}
\hline Find More Notes & Journey of Thinking \\
\hline
\end{tabular}

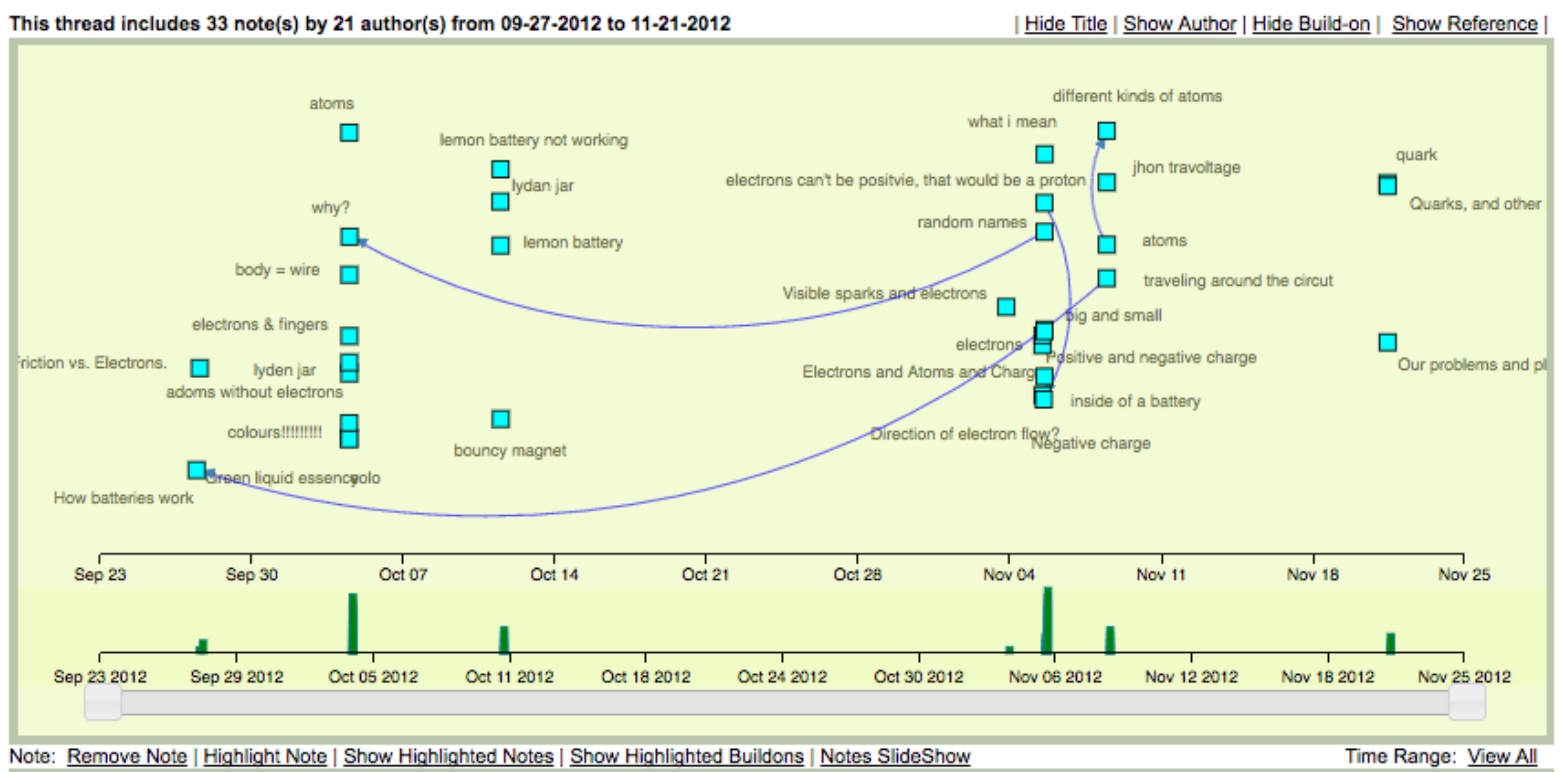

Figure 1. An idea thread showing the unfolding strand of discourse about electrons in the whole inquiry of electricity. Each square represents a note. A line between two notes represents a build-on link. 


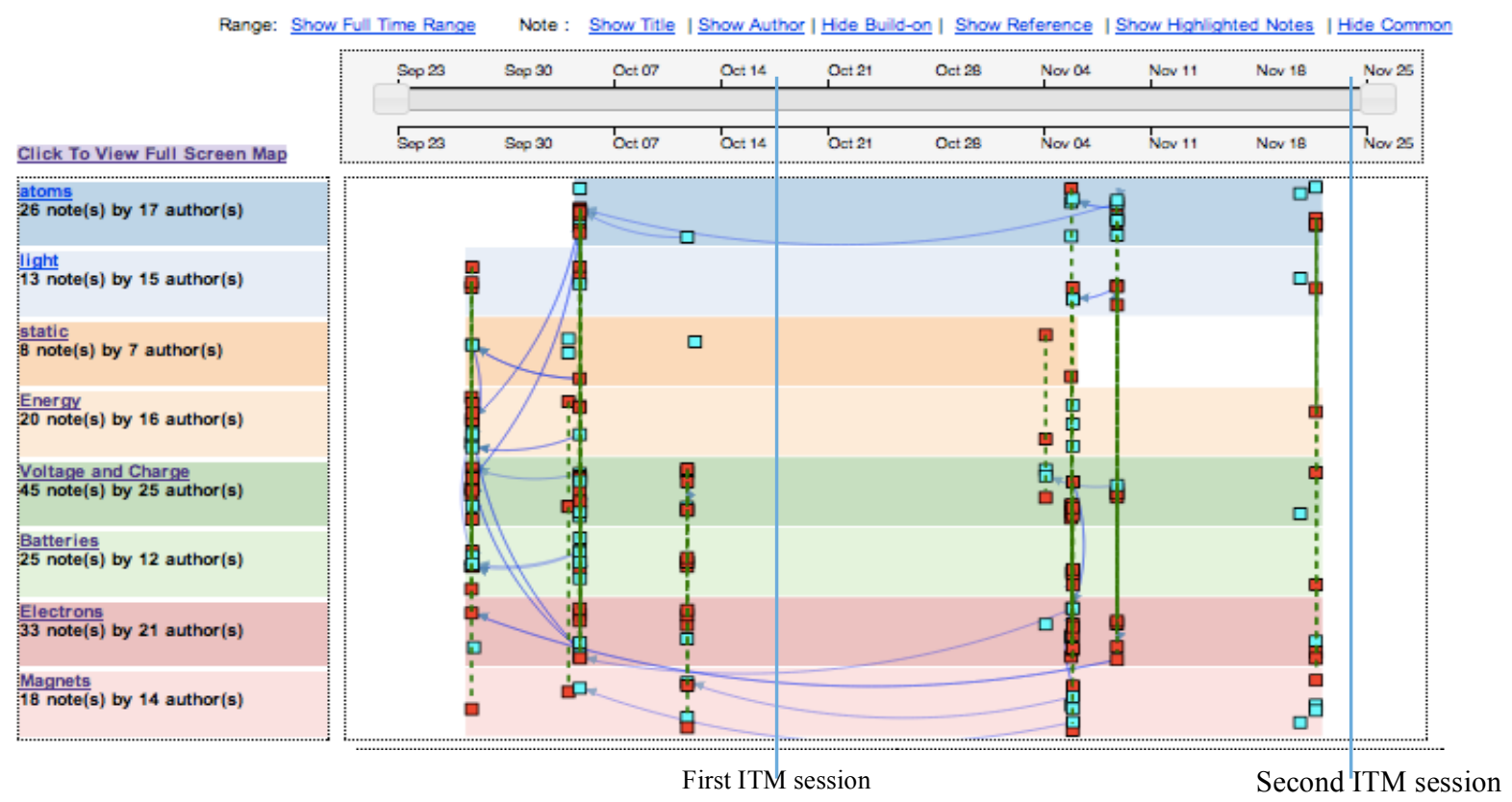

Figure 2. A map of idea threads created by an upper primary school classroom studying electricity. Each colored stripe represents an idea thread. Each square represents a note. A line between two notes represents a build-on link. A dotted vertical line shows notes shared between different threads discussing interrelated objects. The user can hover the mouse over a note to preview its content and open an idea thread by clicking its title. 


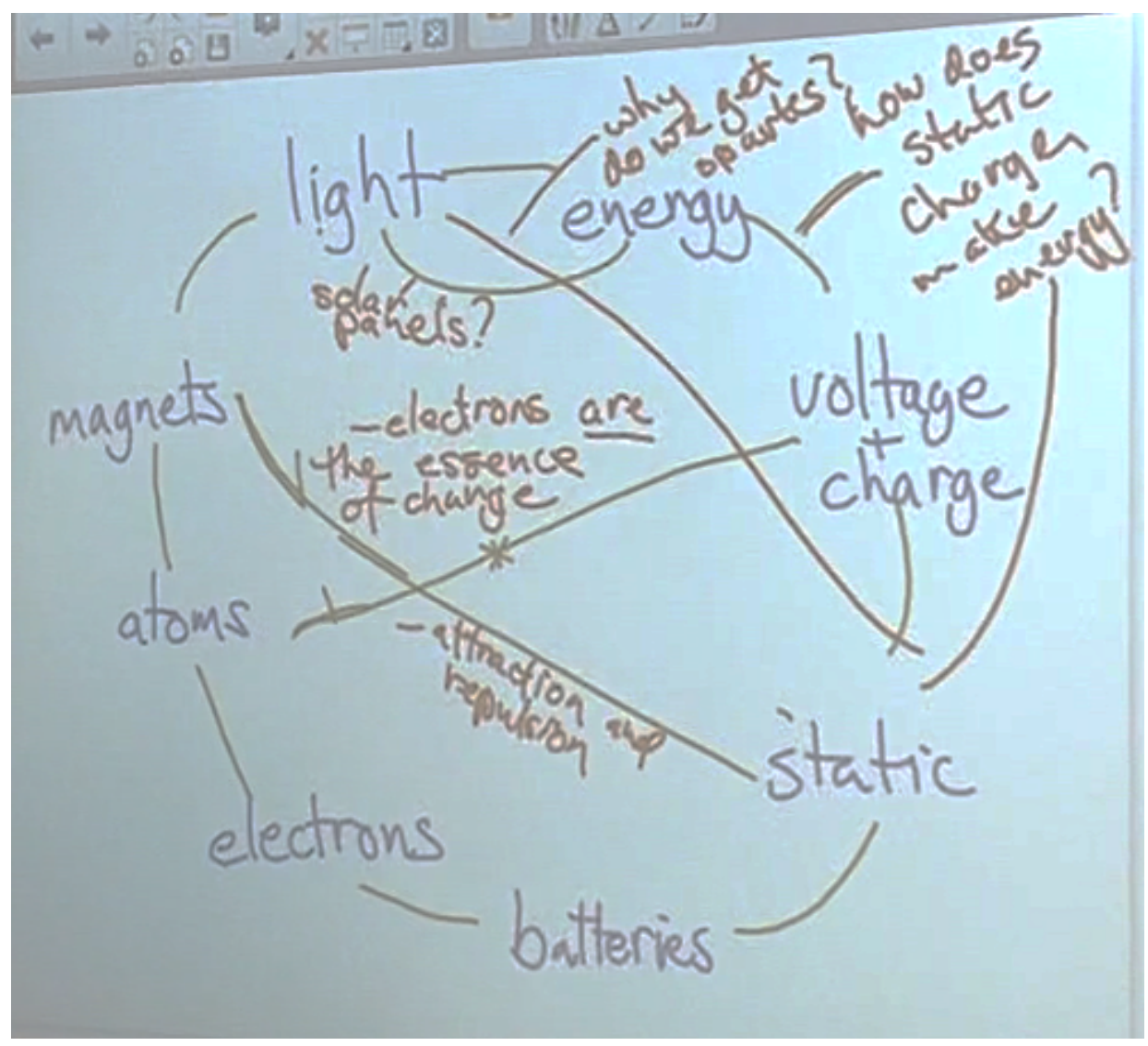

Figure 3. Visual notes of student discussion on the interconnectedness of the eight inquiry topics. 


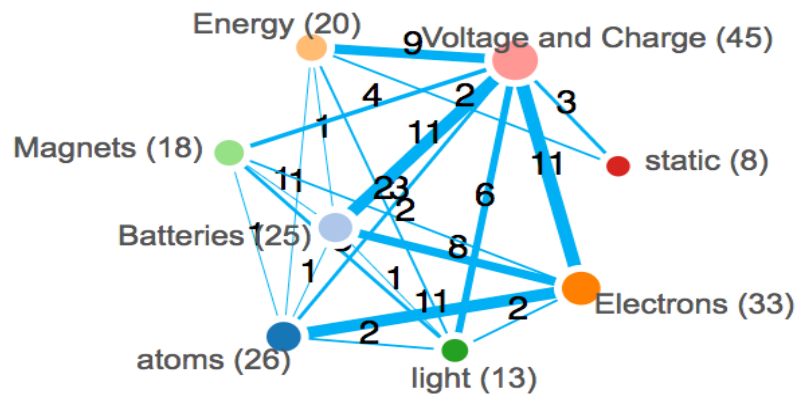

Classroom A

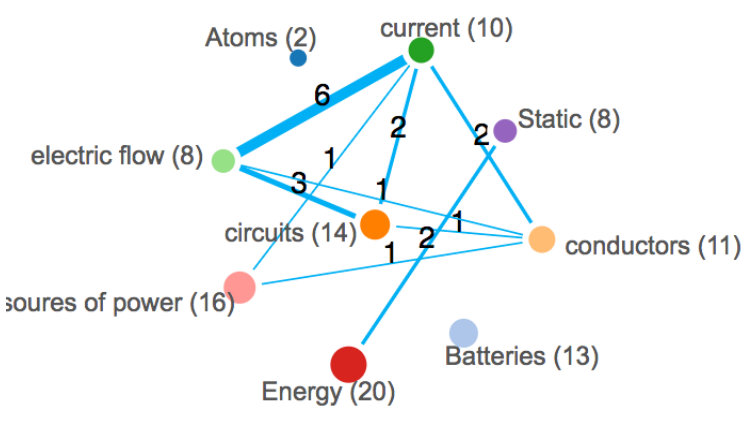

Classroom B

Figure 4. Connections across idea threads through the "bridging notes" that simultaneously addressed multiple topics of inquiry. The number after each thread topic denotes the total number of notes generated in the thread, and the number on each line shows the number of bridging notes between the two linked topics. 


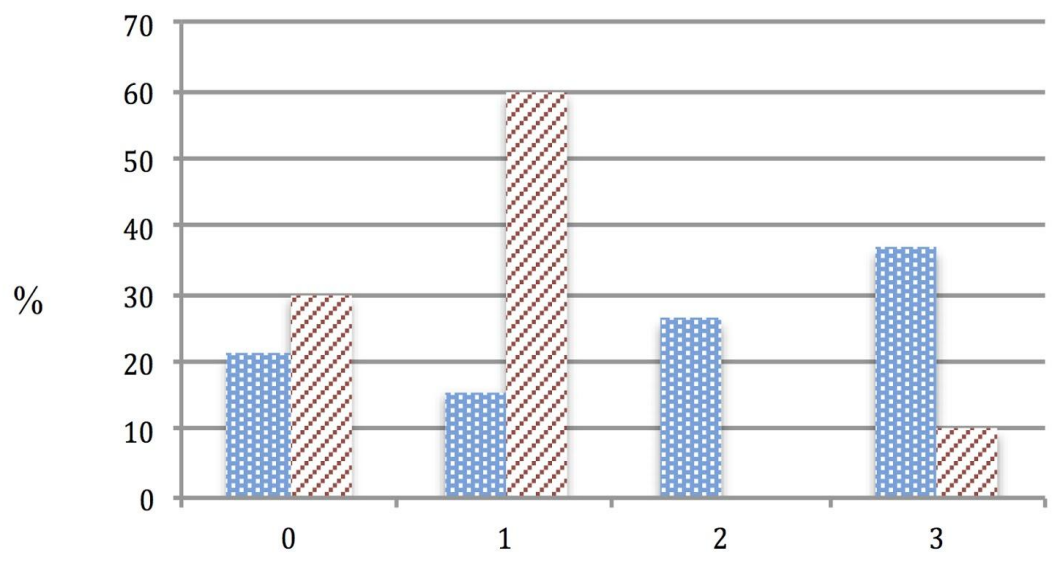

明 Class A

$\%$ Class B

Figure 5. Percentages of students giving different explanations of electricity. The categories include: 0 - no explanation given; 1 - electricity as flow of energy; 2 - electricity as positive and negative charges and currents; and 3 - electricity as the movement of electrically charged particles. 
Table 1

Collective Structures of Knowledge Building Practices.

\begin{tabular}{|c|c|c|}
\hline Focus and dimension & Structural element & Artifacts and resources to reify the structures \\
\hline $\begin{array}{l}\text { Areas and objects of } \\
\text { inquiry: shared frames } \\
\text { about what the } \\
\text { community needs to } \\
\text { investigate and pursue in } \\
\text { a knowledge building } \\
\text { initiative. }\end{array}$ & $\begin{array}{l}\text { - Overarching focus of inquiry; } \\
\text { - Unfolding directions and strands of } \\
\text { inquiry focusing on various objects; } \\
\text { - Framing of common knowledge } \\
\text { base and gaps related to the specific } \\
\text { objects of inquiry. }\end{array}$ & $\begin{array}{l}\text { - Using a mission statement to set the } \\
\text { overarching focus of inquiry (Zhang et al., } \\
\text { 2009); } \\
\text { - Using a tree chart to highlight the } \\
\text { "wondering areas" generated based on } \\
\text { diverse research interests and questions } \\
\text { (Tao et al., 2015); } \\
\text { - Classifying and tagging reading materials } \\
\text { based on the directions of inquiry; } \\
\text { - Co-creating concept chart to show the } \\
\text { objects of inquiry and their relationships, } \\
\text { using various colors to show the status of } \\
\text { progress (Tao et al., 2017); } \\
\text { - Writing a Journey of Thinking synthesis } \\
\text { or portfolio note to document shared } \\
\text { progress and problems in each direction of } \\
\text { inquiry. }\end{array}$ \\
\hline $\begin{array}{l}\text { Participatory structure: } \\
\text { Social configurations } \\
\text { about who work on what } \\
\text { in connection with whom } \\
\text { to advance their } \\
\text { collective knowledge. }\end{array}$ & $\begin{array}{l}\text { - Students' dynamic grouping around } \\
\text { the collective directions of inquiry } \\
\text { for specialized inquiry and shared } \\
\text { responsibility; } \\
\text { - Social spaces and mechanisms for } \\
\text { progress monitoring, sharing, and } \\
\text { connecting. }\end{array}$ & $\begin{array}{l}\text { - Adding student names to the tree chart of } \\
\text { wondering areas to show their } \\
\text { specialization and grouping in the areas of } \\
\text { research; } \\
\text { - Visual tracking of dynamic groups formed } \\
\text { to address different areas of research (Tao } \\
\text { et al., 2017). } \\
\text { - Organization of face-to-face and online } \\
\text { discourse spaces based on the directions of } \\
\text { inquiry to guide student participation } \\
\text { (Zhang et al., 2009). }\end{array}$ \\
\hline $\begin{array}{l}\text { Process structure: Shared } \\
\text { frames about how the } \\
\text { community should } \\
\text { conduct research and } \\
\text { collaborate to advance } \\
\text { collective knowledge. }\end{array}$ & $\begin{array}{l}\text { Shared framing of the overarching } \\
\text { flow of the knowledge building } \\
\text { process; } \\
\text { Ground rules for productive online } \\
\text { discourse and face-to-face talks; } \\
\text { Guidelines and scaffolds for } \\
\text { specific inquiry activities such as } \\
\text { observation, note taking, etc. }\end{array}$ & $\begin{array}{l}\text { - Co-creating a "research cycle" chart to } \\
\text { highlight the overarching process of } \\
\text { knowledge building, as a referential } \\
\text { framework (Tao \& Zhang, in press); } \\
\text { - Co-creating rules of online contributions } \\
\text { through reflection (Zhang et al., 2011); } \\
\text { - Co-designing scaffolds for sharing } \\
\text { experimental findings. }\end{array}$ \\
\hline $\begin{array}{l}\text { Principled values and } \\
\text { beliefs: understandings } \\
\text { of why the community } \\
\text { should operate in certain } \\
\text { ways, as justified based } \\
\text { on shared principles and } \\
\text { values. }\end{array}$ & $\begin{array}{l}\text { - Shared understanding of core } \\
\text { knowledge building principles; } \\
\text { - Social values and norms, such as } \\
\text { respect, responsibility, } \\
\text { perseverance, and mutual care and } \\
\text { support. }\end{array}$ & $\begin{array}{l}\text { - Discussing the social norms and principles } \\
\text { and posts them on the classroom wall; } \\
\text { - Using the knowledge building principles } \\
\text { as a guide for student reflection and } \\
\text { assessment (van Aalst \& Chan, 2007). }\end{array}$ \\
\hline
\end{tabular}


Table 2

The Key Features of ITM to Make Collective Structures Visible.

\begin{tabular}{|l|l|}
\hline Key Feature & Description \\
\hline $\begin{array}{l}\text { Inquiry area and object } \\
\text { organizer }\end{array}$ & $\begin{array}{l}\text { A visual display of the major areas (e.g., circulatory system) and } \\
\text { objects (heart, blood cells, lungs) of inquiry to organize a whole } \\
\text { knowledge building initiative (e.g., the human body inquiry). Students } \\
\text { propose the areas and objects of inquiry, with each object of inquiry } \\
\text { becoming the focus of an idea thread. }\end{array}$ \\
\hline Idea thread & $\begin{array}{l}\text { Visualization of each unfolding strand of inquiry that involves a } \\
\text { sequence of discourse entries investigating a shared object of inquiry, } \\
\text { extending from the first to the last discourse entry. Students enter the } \\
\text { focus (object) of inquiry, write or import the relevant discourse entries, } \\
\text { which are plotted on a timeline as an idea thread. Analytic tools (e.g., } \\
\text { search, topic modeling, contribution type analysis) are created to help } \\
\text { students find and review relevant discourse. }\end{array}$ \\
\hline $\begin{array}{l}\text { Mapping different idea } \\
\text { threads }\end{array}$ & $\begin{array}{l}\text { Visualization of multiple threads and areas of inquiry to show the } \\
\text { whole picture of a knowledge building initiative. Students select areas } \\
\text { and/or threads to map and choose to show specific information such as } \\
\text { cross-thread build-on links and "bridging notes" each belonging to } \\
\text { multiple threads (talking about interrelated topics). }\end{array}$ \\
\hline $\begin{array}{l}\text { Journey of thinking } \\
\text { synthesis }\end{array}$ & $\begin{array}{l}\text { A "Journey of Thinking" document co-authored by students for each } \\
\text { idea thread, which highlights the problem/goal of inquiry, "big ideas" } \\
\text { learned, and deeper issues and actions to be pursued. }\end{array}$ \\
\hline $\begin{array}{l}\text { Participatory role } \\
\text { tracing }\end{array}$ & $\begin{array}{l}\text { Tracing of student specialization and contribution across inquiry areas } \\
\text { and idea threads. Students select an area(s) of inquiry as his/her focus, } \\
\text { with students of shared interests forming flexible collaboration ties. } \\
\text { ITM further retrieves the members' participation in each idea thread as } \\
\text { authors and readers. }\end{array}$ \\
$\begin{array}{l}\text { A cross-community space where students from different classrooms } \\
\text { can view one another's inquiry areas, idea threads, and Journey of } \\
\text { Thinking syntheses; and propose "super talk" topics to discuss } \\
\text { challenging issues. }\end{array}$ \\
\hline
\end{tabular}


Table 3

The Research Questions, Data Analyses, and Intended Outcomes

\begin{tabular}{|l|l|l|}
\hline Research question & Data analysis & Intended outcomes \\
\hline $\begin{array}{l}\text { (a) How does the community co- } \\
\text { construct collective inquiry } \\
\text { structures to frame its shared foci } \\
\text { and unfolding strands of } \\
\text { knowledge practices, with what } \\
\text { interactional input from the } \\
\text { students and their teacher? }\end{array}$ & $\begin{array}{l}\text { Qualitative } \\
\text { analysis of } \\
\text { classroom videos, } \\
\text { observation notes, } \\
\text { and teacher } \\
\text { meeting records. }\end{array}$ & $\begin{array}{l}\text { To provide a detailed account of the } \\
\text { reflective processes and conversations } \\
\text { by which the community co-constructs, } \\
\text { adapts, and uses the collective } \\
\text { structures to guide and deepen its } \\
\text { inquiry work. }\end{array}$ \\
\hline $\begin{array}{l}\text { (b) In what ways does the } \\
\text { reflective structuration with ITM } \\
\text { contribute to improving the } \\
\begin{array}{l}\text { community's knowledge } \\
\text { building interaction and } \\
\text { enhancing student }\end{array}\end{array}$ & $\begin{array}{l}\text { Quantitative and } \\
\text { content analysis of } \\
\text { student online } \\
\text { discourse; } \\
\text { Content analysis of } \\
\text { student summaries } \\
\text { of what they had } \\
\text { learned. }\end{array}$ & $\begin{array}{l}\text { To gauge the impact of reflective } \\
\text { structuration through between- } \\
\text { classroom comparison. The classroom } \\
\text { with ITM-supported reflective } \\
\text { structuration is expected to engage in } \\
\text { more active and connected online } \\
\text { discourse and develop deeper and more } \\
\text { coherent understandings. }\end{array}$ \\
\hline
\end{tabular}


Table 4

Coding of Explanations of How Electricity Works

\begin{tabular}{|l|l|}
\hline Category & Description \\
\hline 0. No explanation & $\begin{array}{l}\text { Students mention related facts or terms, but no explanation is } \\
\text { provided about how electric circuits work. }\end{array}$ \\
\hline $\begin{array}{l}\text { 1. Electricity as flow of } \\
\text { energy }\end{array}$ & $\begin{array}{l}\text { Students describe batteries as the source of energy that provides } \\
\text { electricity. Electricity flows through wires/conductors to the light } \\
\text { bulb. No explanation is given about the mechanism and processes } \\
\text { related to negative and positive charges. }\end{array}$ \\
\hline $\begin{array}{l}\text { 2. Electricity as } \\
\text { positive and negative } \\
\text { charges/currents }\end{array}$ & $\begin{array}{l}\text { Students explain the flow of electricity in terms of positive and } \\
\text { negative charges or currents. For electricity to flow, the wires need } \\
\text { to connect both positive and negative terminals of the battery } \\
\text { towards the bulb to form a closed circuit. }\end{array}$ \\
\hline $\begin{array}{l}\text { 3. Electricity as } \\
\text { movement of } \\
\text { electrically charged } \\
\text { particles }\end{array}$ & $\begin{array}{l}\text { Students mention positive and negative charges and further } \\
\text { understand them in terms of the movement of electrically charged } \\
\text { particles including protons and electrons. Battery is seen as an } \\
\text { active source of electricity by means of chemical reaction enabling } \\
\text { the movement of electrically charged particles. }\end{array}$ \\
\hline
\end{tabular}




\section{Table 5}

The Journey of Thinking Synthesis on Magnets Organized as Three Sections

\begin{tabular}{|c|c|c|}
\hline Our Problems & "Big ideas" we have learned & We need to do more \\
\hline $\begin{array}{l}\text {-We need to understand } \\
\text { how magnets relate to } \\
\text { electricity } \\
\text {-why do magnets throw } \\
\text { compasses off? } \\
\text { - how do magnets work? }\end{array}$ & $\begin{array}{l}\text { - That magnets produce an } \\
\text { invisible magnetic field. } \\
\text { - Magnets have two sides, } \\
\text { one positive one negative. }\end{array}$ & $\begin{array}{l}\text {-I think that we should } \\
\text { experiment with different types } \\
\text { of metal to see which ones are } \\
\text { more magnetic. } \\
\text { - We need to understand the } \\
\text { connection between magnets and } \\
\text { electricity by looking on the } \\
\text { Internet... }\end{array}$ \\
\hline
\end{tabular}




\section{Table 6}

The Number and Percentage of Online Posts Involving Various Discourse Moves

\begin{tabular}{|c|c|c|c|c|c|c|c|c|}
\hline Class & Questioning & $\begin{array}{c}\text { Fact- } \\
\text { seeking } \\
\text { questions }\end{array}$ & $\begin{array}{c}\text { Explanation } \\
\text {-seeking } \\
\text { questions }\end{array}$ & $\begin{array}{c}\text { Initial } \\
\text { wondering } \\
\text { questions }\end{array}$ & $\begin{array}{c}\text { Idea- } \\
\text { deepening } \\
\text { questions }\end{array}$ & Explaining & Evidence & $\begin{array}{c}\text { Integrating } \\
\text { and } \\
\text { applying }\end{array}$ \\
\hline A & $\begin{array}{c}53 \\
37.86 \%\end{array}$ & $\begin{array}{c}9 \\
6.43 \%\end{array}$ & $\begin{array}{c}45 \\
32.14 \%\end{array}$ & $\begin{array}{c}16 \\
11.43 \%\end{array}$ & $\begin{array}{c}37 \\
26.43 \%\end{array}$ & $\begin{array}{c}85 \\
60.71 \%\end{array}$ & $\begin{array}{c}17 \\
12.14 \%\end{array}$ & $\begin{array}{c}14 \\
1.00 \%\end{array}$ \\
\hline B & $\begin{array}{c}22 \\
20.37 \%\end{array}$ & $\begin{array}{c}7 \\
6.48 \%\end{array}$ & $\begin{array}{c}16 \\
14.81 \%\end{array}$ & $\begin{array}{c}18 \\
16.67 \%\end{array}$ & $\begin{array}{c}4 \\
3.70 \%\end{array}$ & $\begin{array}{c}78 \\
72.22 \%\end{array}$ & $\begin{array}{c}2 \\
1.85 \%\end{array}$ & $\begin{array}{c}1 \\
0.09 \%\end{array}$ \\
\hline
\end{tabular}

